\title{
Revision of the genus Cerapanorpa (Mecoptera: Panorpidae) with descriptions of four new species
}

\author{
Kai GAO ${ }^{1}$ \& Bao-Zhen $\mathrm{HUA}^{2, *}$ \\ ${ }^{1,2}$ Key Laboratory of Plant Protection Resources and Pest Management, Ministry of Education, \\ Entomological Museum, College of Plant Protection, Northwest A\&F University, \\ Yangling, Shaanxi 712100, China. \\ ${ }^{*}$ Corresponding author: huabzh@nwafu.edu.cn \\ 1Email: gaokai@nwafu.edu.cn \\ ${ }^{1}$ urn:lsid:zoobank.org:author:B0375303-06B1-4948-95AA-EA6D514A721F \\ ${ }^{2}$ urn:1sid:zoobank.org:author:C02F1E14-1B20-4B92-BA8F-57937D3D3137
}

\begin{abstract}
The genus Cerapanorpa Gao, Ma \& Hua, 2016 is taxonomically revised. Cerapanorpa is confirmed to be endemic to the mountain regions in central China. Nineteen species are recognized in the genus, including four new species: Cerapanorpa baimaensis sp. nov., Cerapanorpa xuebaodinga sp. nov., and Cerapanorpa yanggashana sp. nov. from the Minshan Mountains, and Cerapanorpa taizishana sp. nov. from the northeastern margin of the Qinghai-Tibetan Plateau. Six species are transferred from Cerapanorpa back to Panorpa Linnaeus, 1758. An updated key to species is presented.
\end{abstract}

Keywords. Biodiversity, central China, Minshan Mountains, scorpionfly, taxonomy.

Gao K. \& Hua B.-Z. 2019. Revision of the genus Cerapanorpa (Mecoptera: Panorpidae) with descriptions of four new species. European Journal of Taxonomy 537: 1-23. https://doi.org/10.5852/ejt.2019.537

\section{Introduction}

The genus Cerapanorpa Gao, Ma \& Hua, 2016 was erected for the Panorpa centralis group (Carpenter 1938; Cheng 1957) with Panorpa obtusa Cheng, 1949 as the type species (Gao et al. 2016). Cerapanorpa is primarily recognized by a single finger-like anal horn on the posterior margin of tergum VI in males, and a medigynium bearing two pairs of basal plates and a well-developed elongate axis in females (Gao et al. 2016; Miao et al. 2017). The species of Cerapanorpa have specific mating behaviors and copulatory strategies. The male usually secretes a salivary mass as a nuptial gift to attract the female prior to copulation, and uses its anal horn to clamp the female abdominal segment to maintain copulation (Tong et al. 2018). Their eggs are oval and bear polygonal net-like ridges on the chorion surface ( $\mathrm{Li}$ et al. 2007; Ma et al. 2009). The saprophagous larvae are eruciform, possessing a pair of well-developed compound eyes (Chen et al. 2012) and eight pairs of abdominal prolegs, and usually overwinter as mature larvae in soil cavities (Li et al. 2007; Jiang \& Hua 2015). 
Twenty-two species were originally included in Cerapanorpa, which is distributed in central China and northeastern Asia, separately (Gao et al. 2016; Wang \& Hua 2017). Soon after its establishment, Cerapanorpa was considered paraphyletic with Panorpa based on molecular phylogenetic and chromosomal data (Miao et al. 2019). The species of Cerapanorpa from central China have chromosome number $n=22$, including C. brevicornis (Hua \& Li, 2007), C. byersi (Hua \& Li, 2007), C. dubia (Chou \& Wang, 1981), C. liupanshana Gao, Ma \& Hua, 2016, C. nanwutaina (Chou \& Wang, 1981), C. obtusa (Cheng, 1949), C. protrudens Gao, Ma \& Hua, 2016, C. reni (Chou \& Wang, 1981) and C. sinuata Gao, Ma \& Hua, 2016, whereas $P$. acutipennis Hua, 1998 from the Changbai Mountains in northeastern China has chromosome number $n=23$ (Miao et al. 2017, 2019). The central Chinese species of Cerapanorpa form a monophyletic clade in phylogenetic analyses based on both morphological characters (Ma et al. 2012) and molecular data (Miao et al. 2017, 2019). In contrast, species from northeastern Asia are paraphyletic with Panorpa (Miao et al. 2019). Therefore, the genus Cerapanorpa needs a taxonomic revision.

Strictly speaking, the species of Cerapanorpa are primarily distributed in the Qinling-Bashan Mountains and their adjacent regions (Gao et al. 2016; Wang \& Hua 2017). The westernmost end of Qinling-Bashan Mountains links with the Minshan Mountains and the northeastern margin of the Qinghai-Tibetan Plateau (QTP), respectively (Zhang et al. 2002). Mountains of the latter two regions are enigmatic and heterogeneous, generally harbour numerous neo-endemic species, and are renowned as crucial "biodiversity hotspots" in the northern hemisphere (Myers et al. 2000; Tang et al. 2006; Huang et al. 2006; Hu et al. 2019). Nevertheless, records of Cerapanorpa in the northeastern QTP, especially the Minshan Mountains, are considerably scarce.

Recently, four undescribed species of Cerapanorpa were discovered from these regions, and are described herein. We also utilized multiple characters to revise Cerapanorpa, reassessed its geographic distribution, and updated the identification key.

\section{Material and methods}

The specimens examined are preserved in 75\% alcohol and stored at the Entomological Museum, Northwest A\&F University, Yangling, China (NWAU) or Shanghai Normal University, Shanghai, China (SHNU). Specimens were observed and dissected under a Nikon SMZ1500 stereoscopic zoom microscope. Female genitalia were macerated in cold $6 \% \mathrm{NaOH}$ solution for $3 \mathrm{~min}$ and rinsed with distilled water. Measurements of wings were conducted with a vernier calliper. Adult photographs were taken with a Nikon D7000 digital camera, other images were taken using a Scientific Digital micrography system ZEISS SteREO Discovery.V20 equipped with an Auto-montage imaging system AxioCam IC. All photographs were assembled with Adobe Photoshop CS4.

\section{Abbreviations \\ $\mathrm{A} 1=$ the first abdominal segment (same as other abdominal segments) \\ $\mathrm{T} 1=$ the first tergum (same as other abdominal segments)}

\section{Repositories}

NWAU $=$ Entomological Museum, Northwest A\&F University, Yangling, China

SHNU = Entomological Museum, Shanghai Normal University, Shanghai, China 


\section{Results}

Class Insecta Linnaeus, 1758

Order Mecoptera Packard, 1886

Family Panorpidae Latreille, 1805

Genus Cerapanorpa Gao, Ma \& Hua, 2016

Cerapanorpa Gao, Ma \& Hua, 2016: 94. Type species: Panorpa obtusa Cheng, 1949.

\section{Diagnosis}

Cerapanorpa can be distinguished from other genera of Panorpidae by the following combination of characters: rostrum of adults slender; generally yellowish, brown and black frontally. Meso- and metanotum blackish brown to black. Wing membrane hyaline and held explanate V-shaped over
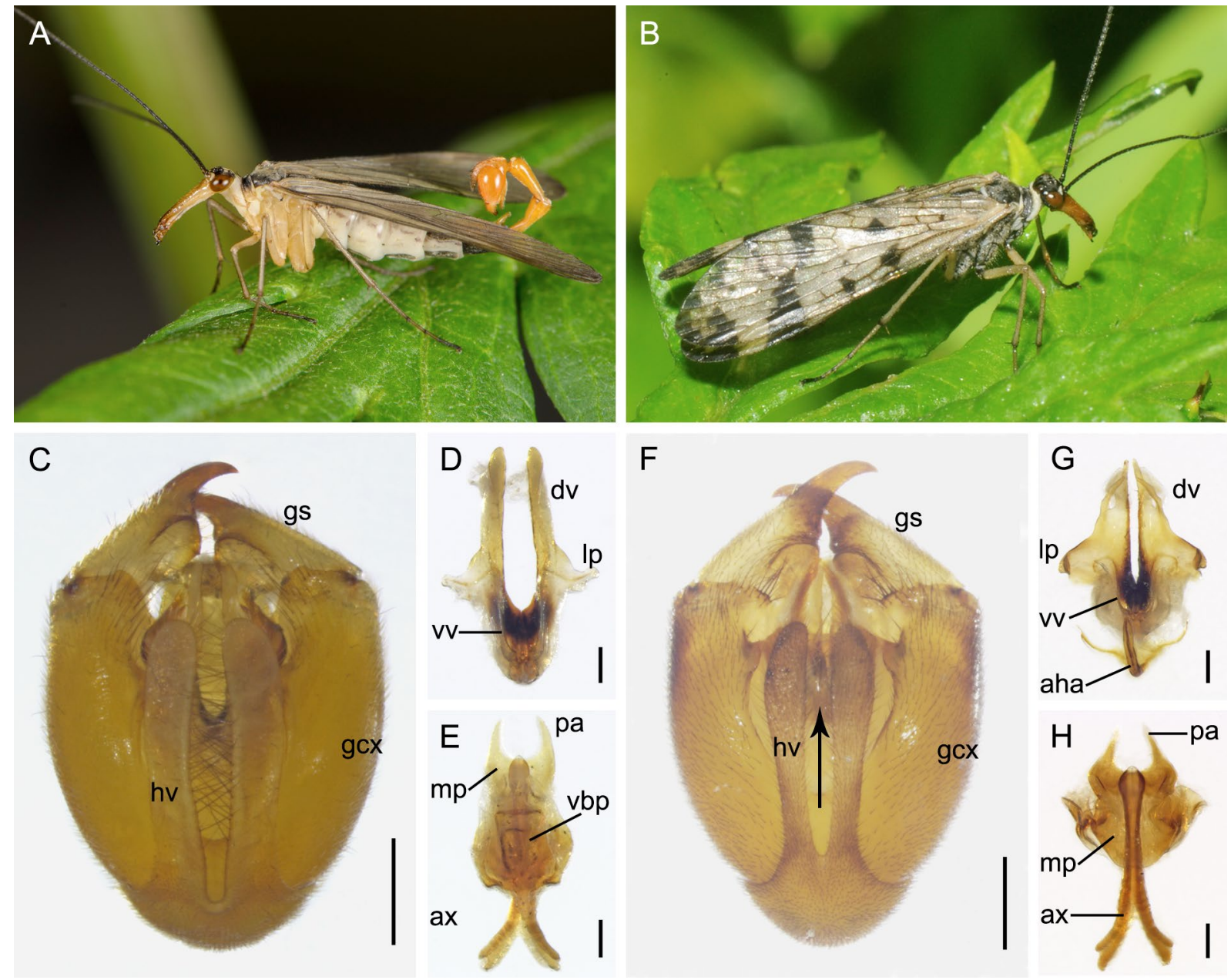

Fig. 1. Comparisons of Cerapanorpa obtusa (Cheng, 1949) (A, C-E) in central China and Panorpa acutipennis Hua, 1998 (B, F-H) from Northeast Asia. A-B. Male live habitus. C, F. Male genital bulb in ventral view. D, G. Aedeagus in ventral view, arrow indicates the aedeagal hamulus. $\mathbf{E}, \mathbf{H}$. Female medigynium in ventral view. Abbreviations: aha = aedeagal hamulus; $a x=a x i s ; d v=$ dorsal valve; $\mathrm{gcx}=$ gonocoxite; $\mathrm{gs}=$ gonostylus; $\mathrm{hv}=$ hypovalve; $\mathrm{lp}=$ lateral process; $\mathrm{mp}=$ main plate; $\mathrm{pa}=$ posterior arm; vbp $=$ ventral basal plate; $v v=$ ventral valve. Scale bars: $C, F=0.5 \mathrm{~mm} ; \mathrm{D}-\mathrm{E}, \mathrm{G}-\mathrm{H}=0.2 \mathrm{~mm}$. 
abdomen at rest (Fig. 1A). Notal organ on T3 short and semicircular; postnotal organ on T4 small, barbshaped and pointed forward. T6 bearing a finger-like anal horn on posterior margin (Fig. 1A), T7 with a narrow groove on dorsal surface. Parameres differing in morphology, simple or seldom furcate, usually bearing spines along mesal margin (Fig. 1C). Aedeagus without aedeagal hamulus; ventral valves of aedeagus extremely short, membranous and transparent; dorsal valves elongated, curved ventrally and not bilobed, bearing a membranous dorsal process on its distal backside (Fig. 1D). Hypandrium (ninth sternum) almost completely represented by a pair of elongate hypovalves (Fig. 1C). Subgenital plate lingulate, slightly or deeply emarginate terminally, bearing long setae on distal portion. Medigynium of female extremely complicated, with a broad main plate, bearing a pair of separated dorsal basal plates on dorsal sides and membranous ventral basal plates on ventral sides (Fig. 1E).

\section{Geographical distribution}

Species of Cerapanorpa are exclusively restricted to the border between Palearctic and Oriental Regions in central China (Fig. 2). Their distribution ranges principally include the Qinling Mountains, the Bashan Mountains, the Liupan Mountains, the Minshan Mountains, the Zhongtiao Mountains, Mount Qiaoshan, Mount Huanglongshan and the northeastern margin of the QTP. Amongst these mountainous regions, the Qinling Mountains have the highest diversity, with a total of ten described species. The type species C. obtusa is widely distributed in the western Qinling Mountains, the Liupan Mountains, Mount Qiaoshan, Mount Huanglongshan and the northeastern margin of the QTP. The second widespread species C. breviconis occurs widely in the Bashan Mountains, the western Qinling Mountains and the eastern Minshan Mountains. Other species are generally endemic to local limited range, present in a few sky islands in mountains.

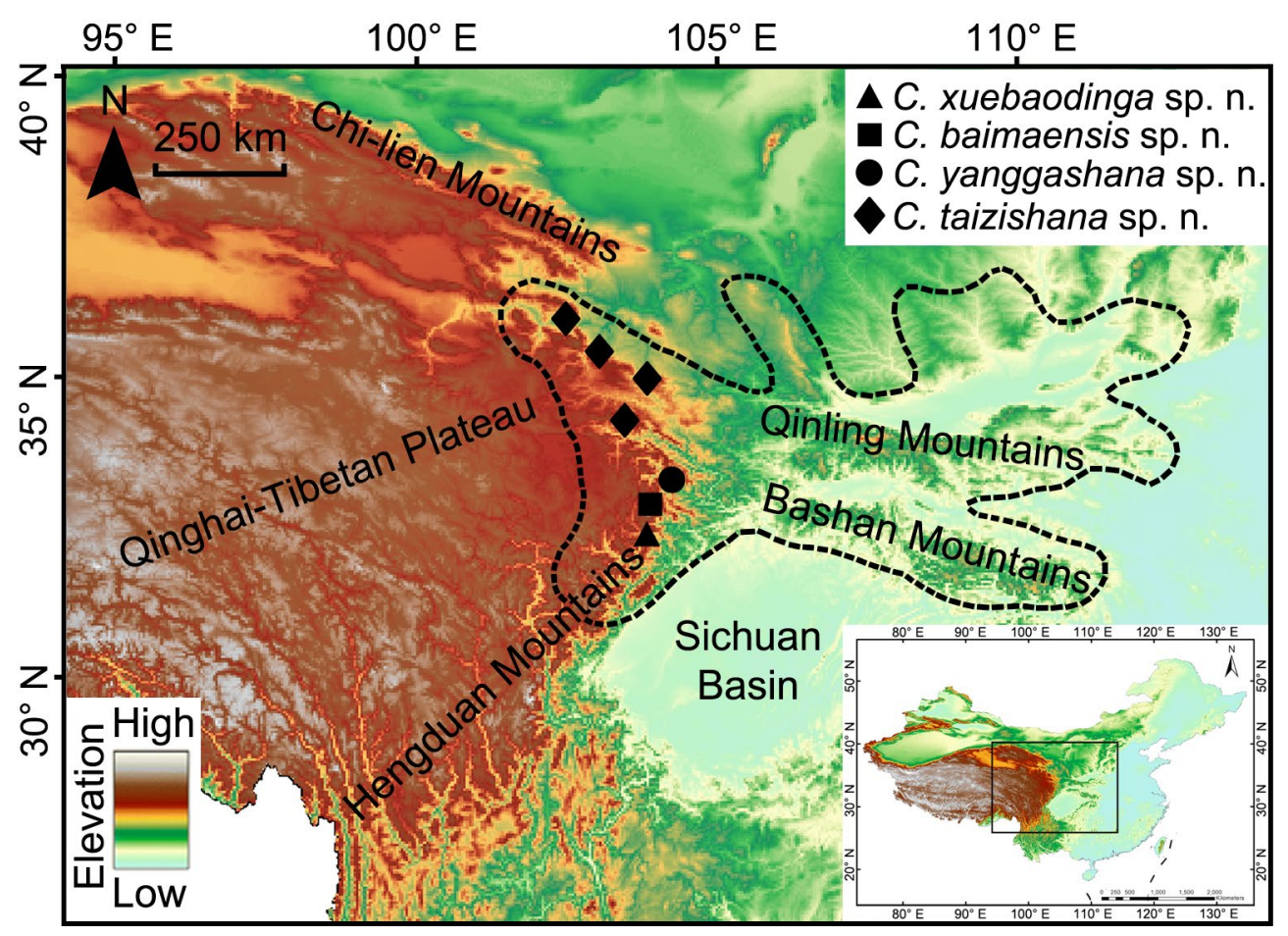

Fig. 2. Species distribution range of the genus Cerapanorpa Gao, Ma \& Hua, 2016 and localities of new species. The limit shown is an approximation defined by collecting localities for specimens of Cerapanorpa. Triangle, C. xuebaodinga sp. nov. Square, C. baimaensis sp. nov. Circle, C. yanggashana sp. nov. Diamond, C. taizishana sp. nov. 


\section{Habitat}

Species of Cerapanorpa are found in the central Chinese mountainous regions, with an altitude approximately from $1400 \mathrm{~m}$ to $2800 \mathrm{~m}$. They generally live on the groundcover under broad-leaf forests (Fig. 3A), mixed forests (Fig. 3B), coniferous forests (Fig. 3C), and on the alpine shrub meadow (Fig. 3D). Their heterogenous microhabitats are universally cool or humid during their flight period.

\section{Remarks}

Gao et al. (2016) transferred P. acutipennis Hua, 1998 in northeastern China and four Japanese species, P. arakavae Miyaké, 1913, P. cornigera MacLachlan, 1887, P. fulvicaudaria Miyaké, 1910 and P. gokaensis Miyaké, 1910 to Cerapanorpa based mainly on the presence of a single anal horn on the posterior margin of T6 in males, but neglected other morphological features. However, these species can be notably differentiated from the true species of Cerapanorpa by the following features (Fig. 1B, $\mathrm{F}-\mathrm{H}$ ): rostrum short and thick (cf. rostrum slender); wings held roof-like (Fig. 1B) over the abdomen at rest (cf. explanate V-shaped (Fig. 1A)); aedeagus with aedeagal hamulus and bilobed dorsal valves (Fig. 1G), whereas the true species of Cerapanorpa lack these features (Fig. 1D). Furthermore, a recent multilocus phylogenetic analysis and cytogenetic evidence (Miao et al. 2019) also confirm that it is necessary to transfer these six species back to Panorpa.

It should be noted that $P$. galloisi Miyaké, 1911 was transferred to Cerapanorpa inadvertently by Gao et al. (2016) because it is not a valid species and had been synonymized with P. cornigera MacLachlan, 1887 by Penny \& Byers (1979). Herein, we correct this unintentional error.

Panorpa horiensis Issiki, 1929 from Taiwan, China is also excluded in the amended Cerapanorpa. Gao et al. (2016) transferred $P$. horiensis to Cerapanorpa based only on the presence of a single anal horn on the posterior margin of T6 in males. However, P. horiensis shows conspicuous difference with the
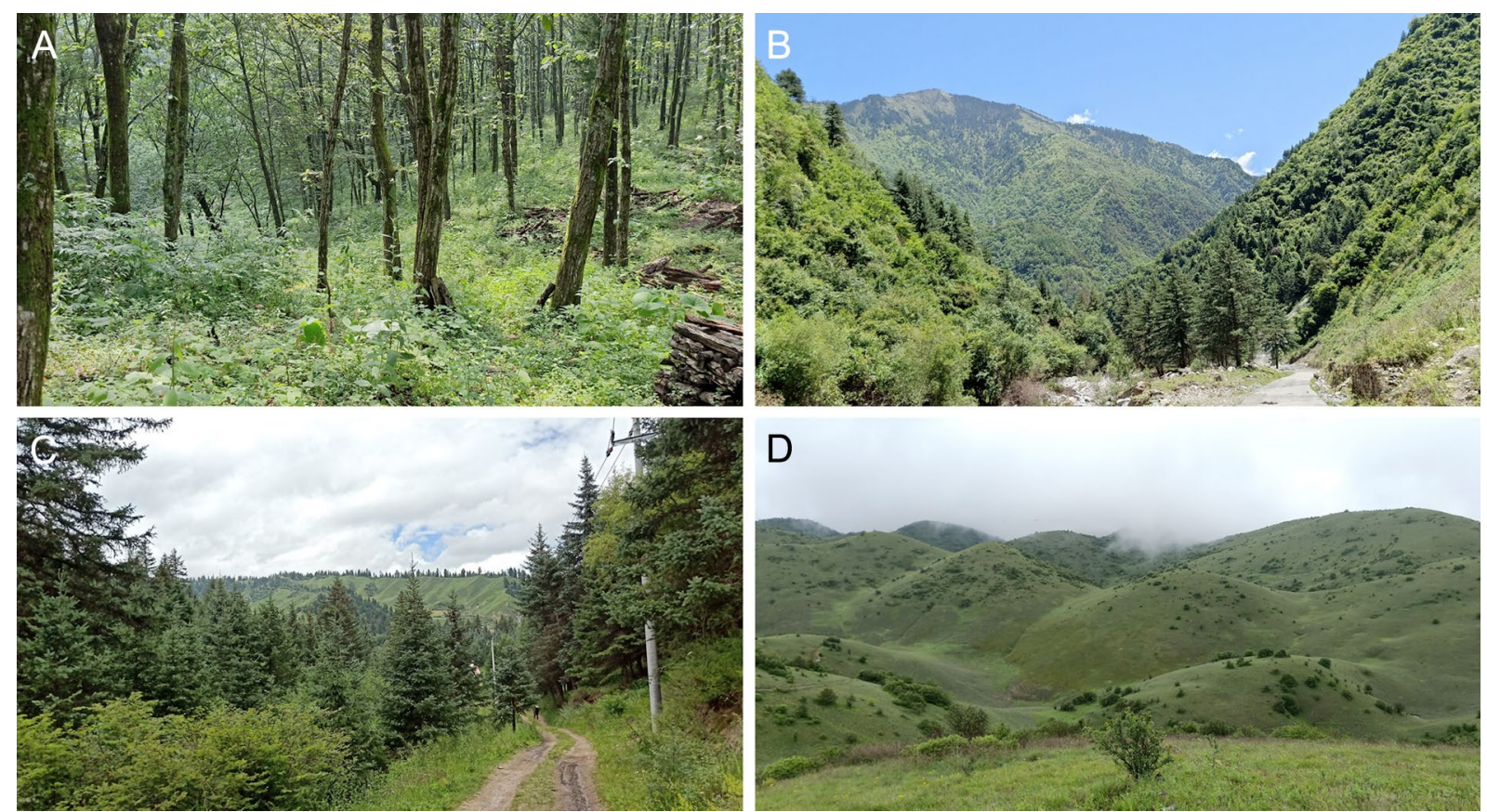

Fig. 3. The habitats of Cerapanorpa Gao, Ma \& Hua, 2016. A. Broad-leaf forest in the Bashan Mountains. B. Mixed forest in the Minshan Mountains. C. Coniferous forest in eastern margin of the QTP. D. Alpine shrub meadow in the Bashan Mountains. 
Cerapanorpa species in appearance and genitalia. It can be easily distinguished from Cerapanorpa by the following features: vertex and occiput yellowish brown (Fig. 4A) (cf. blackish brown ); A6 of male with a single reddish brown conical anal horn (Fig. 4B) (cf. yellowish brown finger-like anal horn); hypovalves of hypandrium broad (Fig. 4C) (cf. slender), with a few short stiff bristles on apex (cf. long bristles along inner margin); paramere stout and broad (Fig. 4C) (cf. slender); dorsal valves of aedeagus without outer apical process (cf. outer apical process unequal-sized). Hence, it is reasonable to transfer P. horiensis back to Panorpa.

A total of 19 valid species of Cerapanorpa are confirmed in this revisionary work. All species are distributed in the mountains of central China, including four new species: C. baimaensis sp. nov., C. xuebaodinga sp. nov., C. yanggashana sp. nov. from the Minshan Mountains, and C. taizishana sp. nov. from the northeastern margin of QTP (Fig. 2).

Key to male species of Cerapanorpa ( $\sigma^{\lambda}$, modified from Gao et al. 2016)

(Male of C. bonis is unknown)

1. T5 with an anal horn on posterior margin

C. bicornifera (Chou \& Wang, 1981)

- $\mathrm{T5}$ without an anal horn on posterior margin

2. Finger-like anal horn on $\mathrm{T} 6$ short and stout, at most 0.2 times as long as T6

- Finger-like anal horn on T6 long, at least 0.3 times as long as T6 3
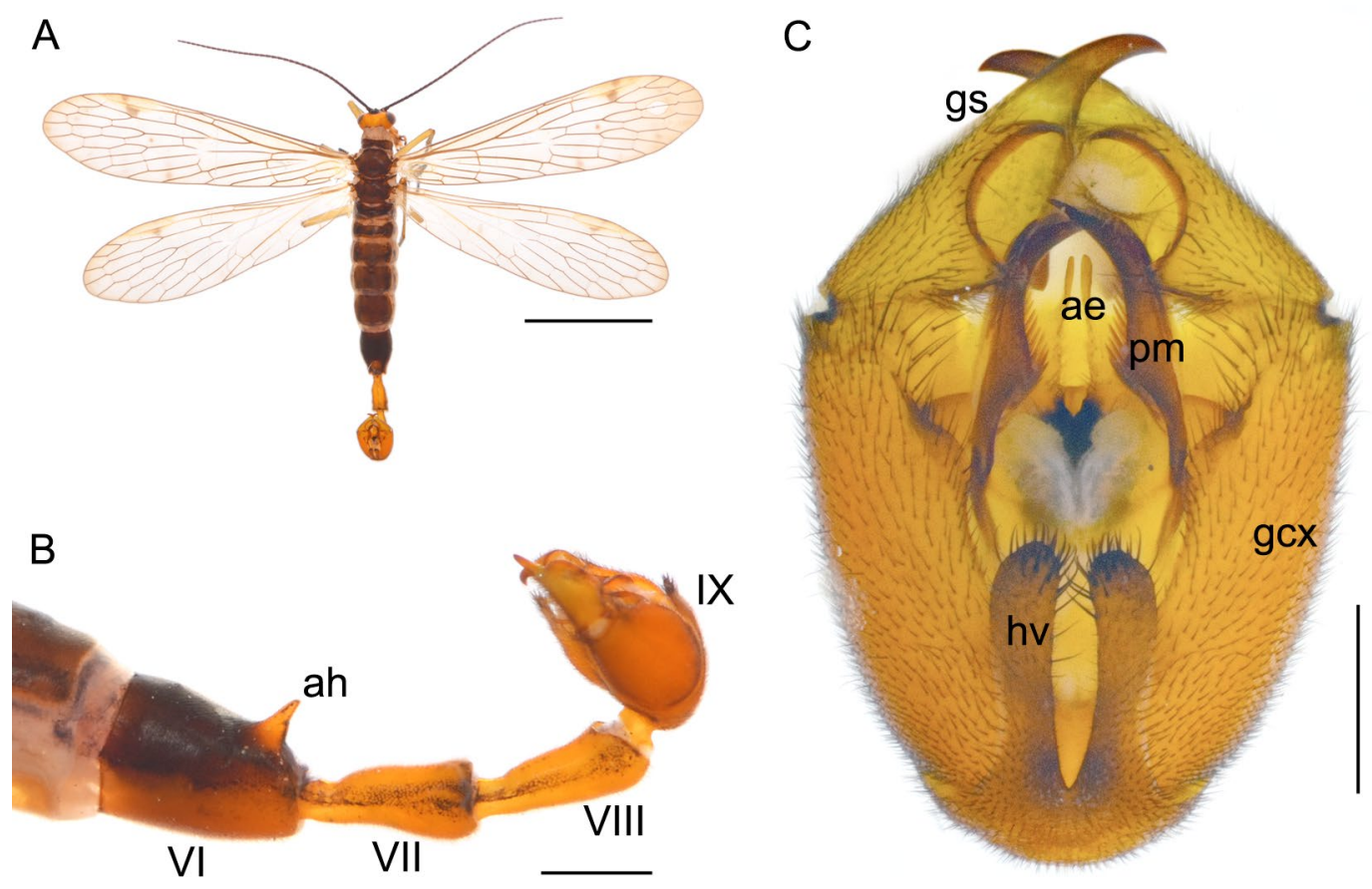

Fig. 4. Panorpa horiensis Issiki, 1929, male from Taiwan, China. A. Habitus in dorsal view. B. Abdomen in lateral view. C. Genital bulb in ventral view. Abbreviations: ae = aedeagus; ah $=$ anal horn; $\mathrm{gcx}=$ gonocoxite; $\mathrm{gs}=$ gonostylus; $\mathrm{hv}=$ hypovalve; $\mathrm{pm}=$ paramere. Scale bars: $\mathrm{A}=5 \mathrm{~mm} ; \mathrm{B}=1 \mathrm{~mm}$; $\mathrm{C}=0.5 \mathrm{~mm}$. 
3. Paramere with thin stalk, then abruptly swollen into broad plate from middle portion, bearing long stout spines along inner margin .....

- Paramere slightly broader than its stalk, with apical portion lanceolate or slightly curved, bearing fine spines along inner margin

4. Paramere quite short, only reaching the base of dorsal valves, quadrate plate above the stalk, with an L-shaped subapical branch

- Paramere palmate in the middle, without subapical branch

5. Paramere reaching posterior margin of gonocoxite, lanceolate at apex, with spines much longer than width at where they inserted; dorsal valve tapering towards apex

C. centralis (Tjeder, 1936)

- Paramere exceeding posterior margin of gonocoxite, curved medially at apex; dorsal valve not tapering towards apex

C. baimaensis sp. nov.

6. Paramere generally linear, only slightly thicker than stalk, bearing a column of very short spines ...7

- Paramere broad and flat above the stalk, significantly broader than its stalk

7. Paramere curved almost at a right angle at base; wing membrane with conspicuous dark-brown markings; middle and hind legs with coxae and trochanters brownish black

C. reni (Chou \& Wang, 1981)

- Paramere slightly curved apically; wing membrane hyaline, only with faint apical band or without markings; all legs with coxae and trochanters yellowish

8. Paramere yellowish brown and blunt apically, reaching middle of gonostylus, bearing spines along inner margin

C. dubia (Chou \& Wang, 1981)

- Paramere dark brown, reaching apex of gonocoxite, bearing a thorn at apex and spines on the dorsum C. liupanshana Gao, Ma \& Hua, 2016

9. Paramere sinuate or geniculate 10

- Paramere straight lanceolate, or somewhat bending medially 15

10. Paramere strongly sinuate and curved posteriorly, with dense spines along inner margin .11

- Paramere slightly sinuate or geniculate on apical portion; dorsal valves of aedeagus long, reaching apex of gonocoxite or longer

11. Paramere nearly bow-shaped; dorsal valves of aedeagus with truncate apex and membranous apical process C. sinuata Gao, Ma \& Hua, 2016

- Paramere hook-shaped; dorsal valves of aedeagus tapering toward apex and with large L-shaped apical process

C. taizishana sp. nov.

12. Paramere columnar and slightly sinuate dorsally on apical portion; hypovalves of hypandrium slender and dramatically elongate, extending to base of gonostylus

C. yanggashana sp. nov.

- Paramere geniculate on apical portion; hypovalves of hypandrium extending over middle of gonocoxite

13. Rostrum blackish brown to black; A6 entirely black; paramere bearing short ventral spines at apex ... C. nanwutaina (Chou \& Wang, 1981)

- Rostrum yellowish to reddish brown; paramere with comb-like long spines along medial margin 
14. Hypovalves slender, with sparse stout bristles along inner margins; dorsal valves of aedeagus brawny, slightly expanded apically

- Hypovalves broad, with dense long bristles along inner margins; dorsal valves of aedeagus elongated and slender apically C. obtusa (Cheng, 1949)

15. Paramere extending to middle of gonostylus 16

- Paramere extending nearly to apex of gonostylus or beyond 17

16. Wings only with faint indication pterostigma and apical band; hypovalve with a regular column of bristles on medial margin; paramere with spines from its middle length

.C. funiushana (Hua \& Chou, 1997)

- Wings with prominent pterostigmal band and apical band; hypovalve with bristles along medial margin; paramere bearing spines above its stalk ...... C. wangwushana (Huang, Hua \& Shen, 2004)

17. Wings without markings; paramere extending beyond gonostylus, with spines shorter than the width at where they inserted along its medial margin C. protrudens Gao, Ma \& Hua, 2016

- Wings with clear pterostigmal band and apical band; paramere nearly reaching apex of gonostylus, bearing spines longer than wide at where inserted along medial margin

C. emarginata (Cheng, 1949)

Cerapanorpa baimaensis sp. nov.

urn:1sid:zoobank.org:act:262BA55A-63F2-49E7-85DD-BDE0CE2C1F25

Figs 5-6

\section{Diagnosis}

The new species can be easily separated from its congeners by the following combination of features: rostrum uniformly darkish brown (Fig. 5C); parameres with dense long spines along inner margin, somewhat curved medially, exceeding apex of gonocoxites (Fig. 6A, D); female main plate flat and intensely broaden in basal half; ventral basal plates translucent and ridgy at medial base, covering twothirds of the main plate; axis short, slightly extending beyond the main plate (Fig. 6F-G).

\section{Etymology}

The specific name refers to the type locality, Baima Town.

\section{Type material}

\section{Holotype}

CHINA • O'; Sichuan Province, Pingwu County, Baima Town; 3244'09" N, 104¹8'48" E; 2000-2200 m a.s.1.; 23 Jul. 2017; Kai Gao \& Yuan Hua leg.; NWAU.

\section{Paratypes}

CHINA • 1 §ิ, 2 q $q$; same collection data as for holotype; 5 Jun. 2018; Kai Gao \& Yu-Ru Yang leg.; NWAU.

\section{Description}

\section{Male}

HEAD. Frons, vertex and occiput black. Rostrum uniformly darkish brown, mandibles brown; Maxillary and labial palpi brownish and darkening towards apex (Fig. 5C). Antennae black, with 40-43 segments. 
THorax. Pronotum black, with 8-12 stout setae along anterior margin. Meso- and metanotum entirely black (Fig. 5D). Pleura light ivory. Legs pale yellow, with distal tarsomere blackish. Forewing length 13.9$14.7 \mathrm{~mm}$, width 3.4-3.8 $\mathrm{mm}$. Wing membrane hyaline, only with significantly degenerated pterostigmal band; Hindwing length $12.5-13.8 \mathrm{~mm}$, width $3.3-3.6 \mathrm{~mm}$, similar to forewing in markings (Fig. 5A).

ABDomen. A1-A5 terga and sterna black. Notal organ on T3 not prominent, a hook-shaped postnotal organ on T4 projecting forward. A6 mostly black, with a yellow finger-like anal horn on its posterior margin. A7 and A8 yellowish brown and elongate; A7 with a narrow groove at base, slightly constricted at basal half and slightly wider toward apices. A8 as long as A7, gradually thickening apically (Fig. 5E).

Genitalia. Genital bulb elliptical and yellowish brown (Fig. 6A-D). Epandrium with a deep U-shaped terminal emargination between two finger-like setose lobes, bearing long bristles on distal portion (Fig. 6C). Hypovalves slender, bearing neat and dense bristles along inner margin (Fig. 6A). Gonocoxite with two small protuberances on ventral submedian margin. Gonostylus much shorter than gonocoxite, with an indistinct middle tooth and a large basal process (Fig. 6A, D). Parameres somewhat curved medially, bearing dense long spines along inner margin, slightly exceeding apex of gonocoxite (Fig. 6D). Dorsal valves of aedeagus elongate and curved apically, reaching distal border of gonocoxite; ventral valves membranous, weakly developed; lateral process small, from base of dorsal valves (Fig. 6E).

\section{Female}

Head, thorax and abdomen. Similar to males in coloration. Forewing length 13.5-15.4 mm, width $3.5-3.9 \mathrm{~mm}$, similar to male in coloration and wing patterns; hindwing length $13.3-15.0 \mathrm{~mm}$, width 3.3-3.6 mm, similar to forewing (Fig. 5B).

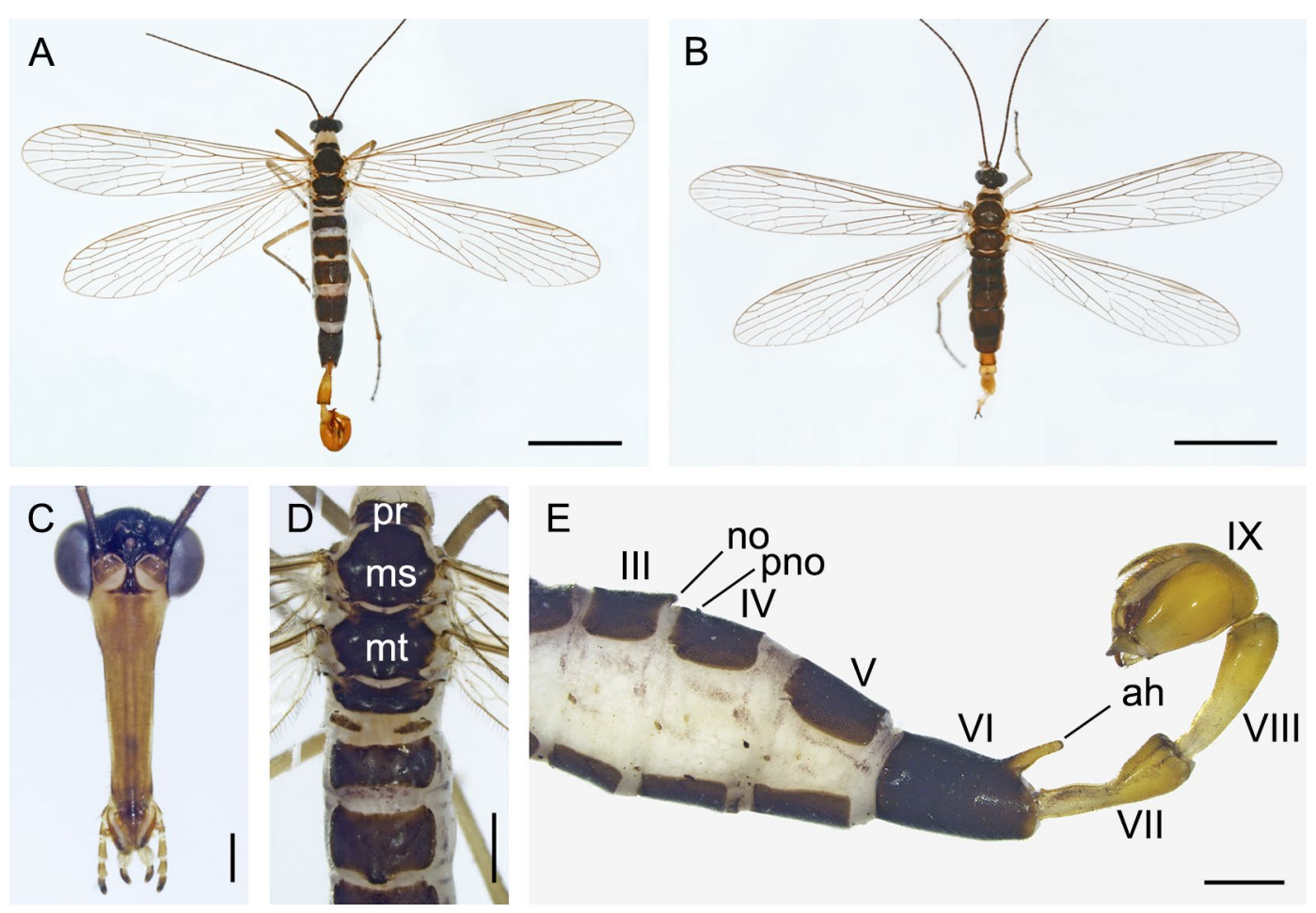

Fig. 5. Adults of Cerapanorpa baimaensis sp. nov. A. Male habitus in dorsal view. B. Female habitus in dorsal view. C. Male head in frontal view. D. Dorsum of male. E. Male abdomen in lateral view. Abbreviations: $\mathrm{ah}=$ anal horn; $\mathrm{ms}=$ mesonotum; $\mathrm{mt}=$ metanotum; no $=$ notal organ; pno $=$ postnotal organ; $\mathrm{pr}=$ pronotum. Scale bars: $\mathrm{A}-\mathrm{B}=5 \mathrm{~mm} ; \mathrm{C}=0.5 \mathrm{~mm}$; $\mathrm{D}-\mathrm{E}=1 \mathrm{~mm}$. 
Genitalia. Subgenital plate elliptical, shallowly emarginate terminally, bearing long setae on distal portion (Fig. 6H). Medigynium small and weakly sclerotized; main plate flat, intensely broadened in basal half (Fig. 6G). Paired posterior arms gradually tapering apically, approximately forming a quadrate emargination (Fig. 6F-G). Ventral basal plates translucent and ridgy at medial base, covering two-thirds of the main plate (Fig. 6F). Paired dorsal basal plates reniform and membranous (Fig. 6G). Axis short and poorly developed, extending slightly beyond the main plate (Fig. $6 \mathrm{~F}-\mathrm{G}$ ).

\section{Distribution}

Sichuan Province, China.

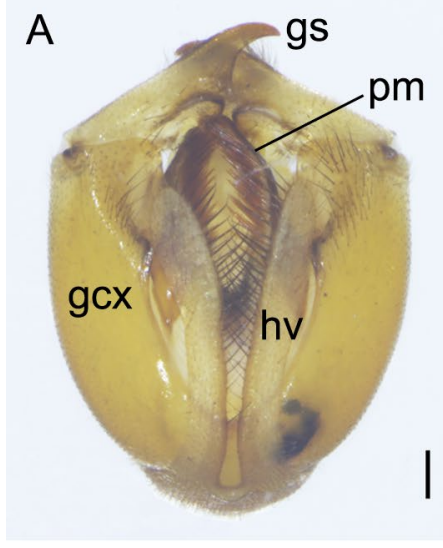

D

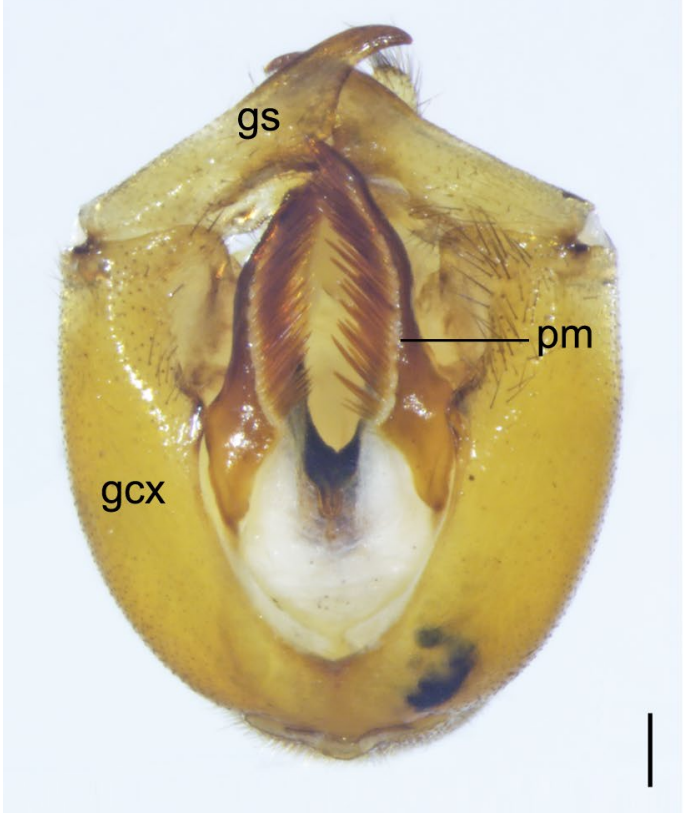

B
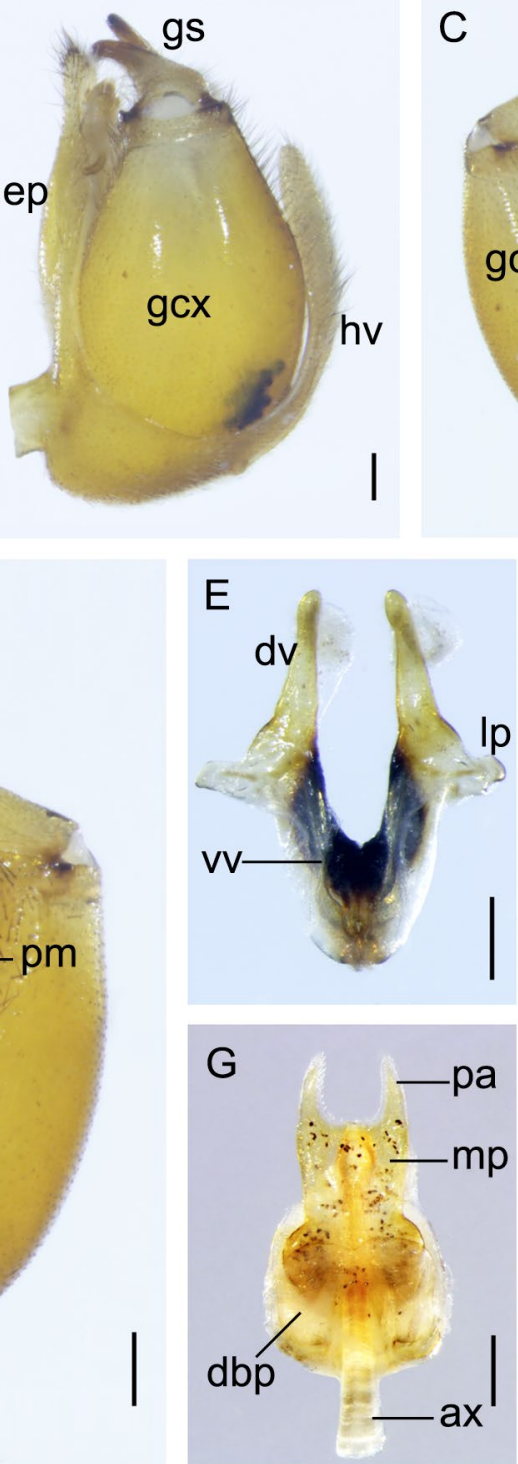

C

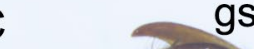
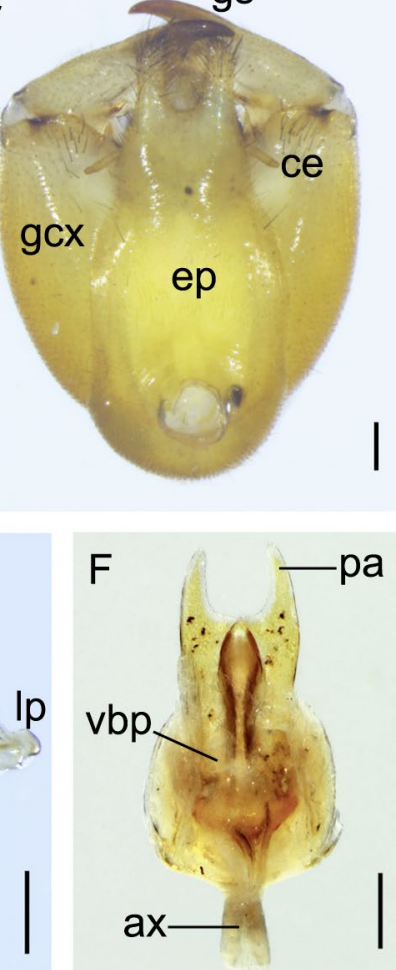

$\mathrm{H}$

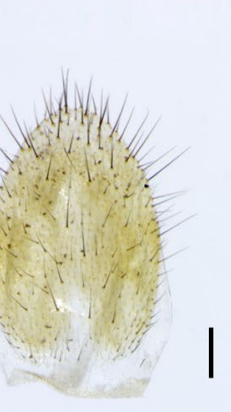

Fig. 6. Genitalia of Cerapanorpa baimaensis sp. nov. A-C. Male genital bulb in ventral, lateral, and dorsal views. D. Male genital bulb with hypandrium removed in ventral view. E. Aedeagus in ventral view. F-G. Female medigynium in ventral and dorsal views. H. Female subgenital plate in ventral view. Abbreviations: $\mathrm{ax}=$ axis; ce $=$ cercus; $\mathrm{dbp}=$ dorsal basal plate; $\mathrm{dv}=$ dorsal valve; $\mathrm{ep}=$ epandrium; $\mathrm{gcx}=$ gonocoxite $; \mathrm{gs}=$ gonostylus $\mathrm{hv}=$ hypovalve $; \mathrm{l}=$ lateral process $; \mathrm{mp}=$ main plate $; \mathrm{pa}=$ posterior arm; $\mathrm{pm}=$ paramere; $\mathrm{vbp}=$ ventral basal plate; $\mathrm{vv}=$ ventral valve. Scale bars: $0.2 \mathrm{~mm}$. 


\section{Remarks}

Cerapanorpa baimaensis sp. nov. resembles C. byersi (Hua \& Li, 2007) and C. centralis (Tjeder, 1936) in appearance, but can be easily identified by the specific shape of the male paramere and aedeagus, especially the ridgy ventral basal plates of medigynium in female.

\section{Cerapanorpa taizishana sp. nov.} urn:1sid:zoobank.org:act:512DF581-649E-458E-8966-AC7B1301C4A2

Figs $7-8$

\section{Diagnosis}

The new species differs from its congeners primarily in the following features: rostrum uniformly brownish black anteriorly (Fig. 7C); hypovalves thin at base, gradually broadened toward apex (Fig. 8A); parameres long, hook-shaped, bearing long spines along inner medial margin (Fig. 8A); dorsal valves of aedeagus tapering abruptly toward apex, curved ventrally, bearing a large L-shaped dorsal process (Fig. 8E-F); female medigynium with a pair of large and oblong dorsal basal plates, approximately as long as half the main plate.

\section{Etymology}

The specific epithet is derived from the type locality, Taizishan (Mount Prince).

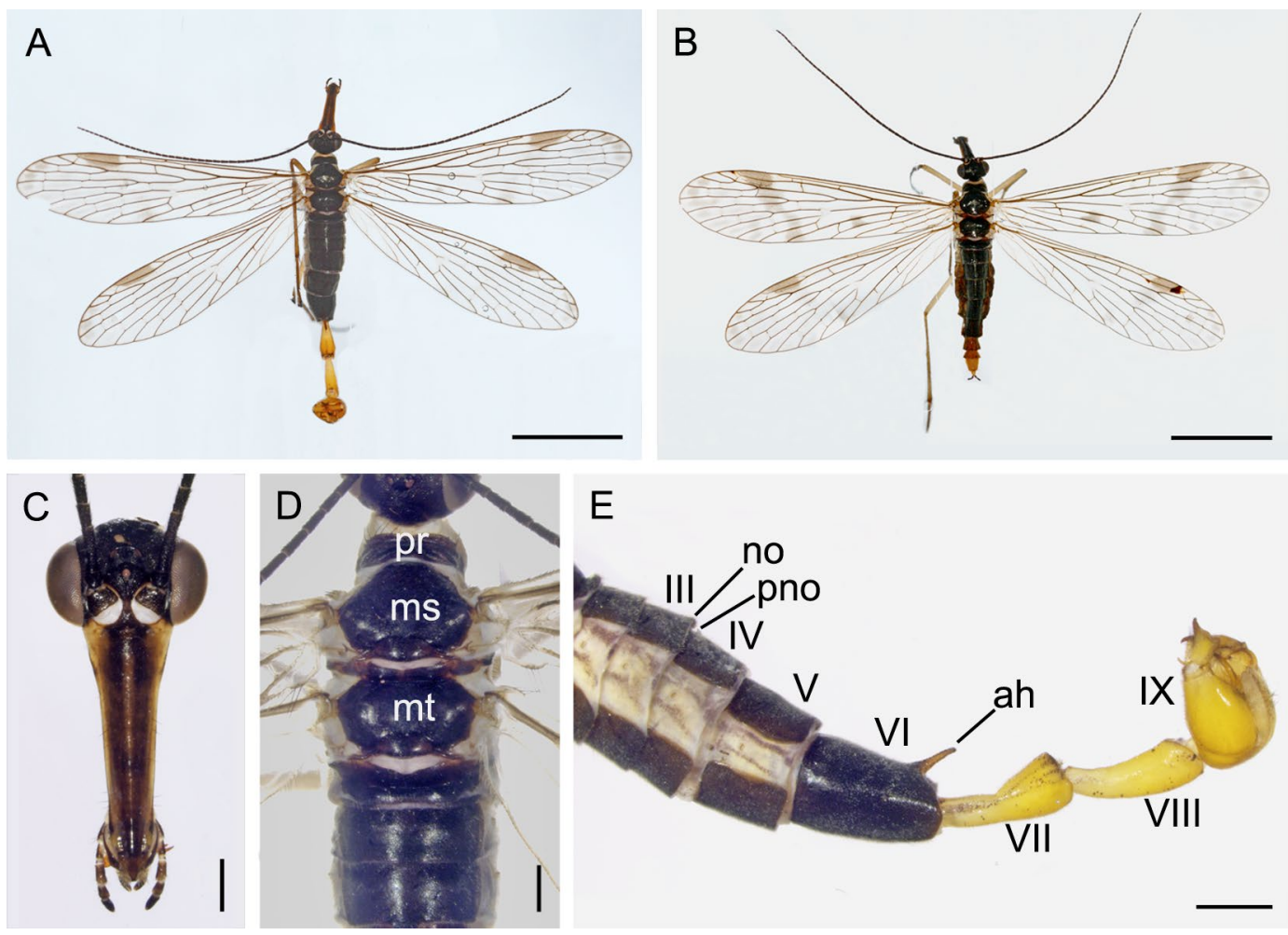

Fig. 7. Adults of Cerapanorpa taizishana sp. nov. A. Male habitus in dorsal view. B. Female habitus in dorsal view. C. Male head in frontal view. D. Dorsum of male. E. Male abdomen in lateral view. Abbreviations: $\mathrm{ah}=$ anal horn; $\mathrm{ms}=$ mesonotum; $\mathrm{mt}=$ metanotum; no $=$ notal organ $;$ pno $=$ postnotal organ; $\mathrm{pr}=$ pronotum. Scale bars: $\mathrm{A}-\mathrm{B}=5 \mathrm{~mm} ; \mathrm{C}-\mathrm{E}=0.5 \mathrm{~mm}$. 


\section{Type material}

Holotype

CHINA - गे; Gansu Province, Hezheng County, Songmingyan National Forest Park; 35 $13^{\prime} 08^{\prime \prime}$ N, 103²4'17" E; 2400-2600 m a.s.l.; 1 Aug. 2018; Kai Gao \& Yu-Ru Yang leg.; NWAU.

\section{Paratypes}

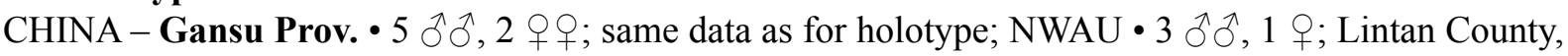

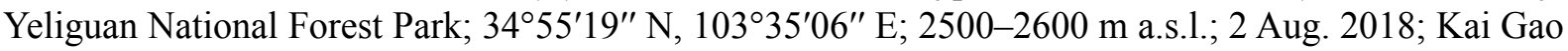
\& Yu-Ru Yang leg.; NWAU • 1 ơ; Tewo County, Comai Peak; 3404'19" N, 10330'06" E; 2400-2600 m a.s.l.; 22 Jul. 2018; Kai Gao leg.; NWAU. - Qinghai Prov.・ 1 ग, 1 \%; Xunhua County, Mengda Nature Reserve; 2200-2500 m a.s.1.; 24 Jul. 2004; Hu, Tang \& Zhu leg.; SHNU.

\section{Description}

Male

HEAD. Frons, vertex and occiput black. Compound eyes dark grey. Rostrum brownish black anteriorly, light brown laterally, mandibles dark brown; labial and maxillary palps light brown with distal segments dark brown (Fig. 7C). Antennae filiform and black with 38-42 flagellomeres.

THORAX. Pronotum blackish brown, with 8-12 setae along its anterior margin; meso- and metanotum black (Fig. 7D). Pleura light grayish yellow. Legs pale yellow with a pair of black apical spurs; tarsi yellowish brown and darkened toward apices. Forewing length $11.8-12.3 \mathrm{~mm}$, width $2.9-3.1 \mathrm{~mm}$. Wing membrane hyaline, only with degenerated brown pterostigma and faint apical band. Hindwing length 11.6-12.0 mm, width $2.7-3.0 \mathrm{~mm}$, similar to forewings in pattern (Fig. 7A).

ABDomen. A1-A5 terga and sterna entirely black, ivory on pleural membrane (Fig. 7E). Notal organ on posterior margin of T3 very short and not prominent. T4 bearing a small harb-shaped postnotal organ. T6 uniformly brownish black, with a brown finger-like anal horn on posterior margin (Fig. 7E). A7-A8 yellowish and elongate, slightly restricted at base, gradually wider toward apices. A7 with a narrow groove on dorsal surface (Fig. 7E).

Genitalia. Genital bulb nearly globular, yellowish brown (Fig. 8A-C). Epandrium broad basally, narrowing toward apex, with a deep U-shaped terminal emargination between two stout setose lobes (Fig. 8C). Paired hypovalves thin basally, broadening toward apex, bearing long bristles along inner margins (Fig. 8A). Gonocoxite with very small concave area on apical inner margin. Gonostylus with a large basal process and an indistinct middle tooth on medial margin, and bearing a bundle of stout setae dorsally on basal process (Fig. 8D). Parameres long and hook-shaped, extending well beyond the apex of gonocoxite, bearing long spines along inner medial margin; apex of paramere bearing a brown stout spine, pointed apically (Fig. 8A). Dorsal valves of aedeagus short, tapering abruptly toward apex and curved ventrally, bearing a large L-shaped dorsal process (Fig. 8E-F); ventral valves membranous and short; lateral process prominent and curved ventrally (Fig. 8E-F).

\section{Female}

HeAd, THORAX AND ABDOMEN. Similar to male in coloration and patterns. Forewing length 12.9-13.2 mm, width 2.9-3.3 mm; wing pattern similar to male, except for more extensive wing markings. Hindwing length 11.8-12.2 mm, width $2.8-3.1 \mathrm{~mm}$, similar to forewing (Fig. 7B).

GenitaLia. Subgenital plate lingulate, with a shallow V-shaped incision at apex, bearing long setae on lateral distal part (Fig. 8I). Main plate of medigynium narrow basally, gradually broadening toward apex. Paired posterior arms tapering toward apex, forming a broad trapeziform emargination (Fig. 8G-H); ventral basal plates translucent, folded ventro-laterally, covering two-thirds of main plate (Fig. 8G); 
paired dorsal basal plates large and oblong, approximately as long as half the main plate, more sclerotized than ventral basal plates (Fig. $8 \mathrm{H}$ ); anterior part of axis bifurcated, extending anteriorly less than half its length beyond main plate (Fig. 8G-H).

\section{Distribution}

Gansu and Qinghai Provinces, China.
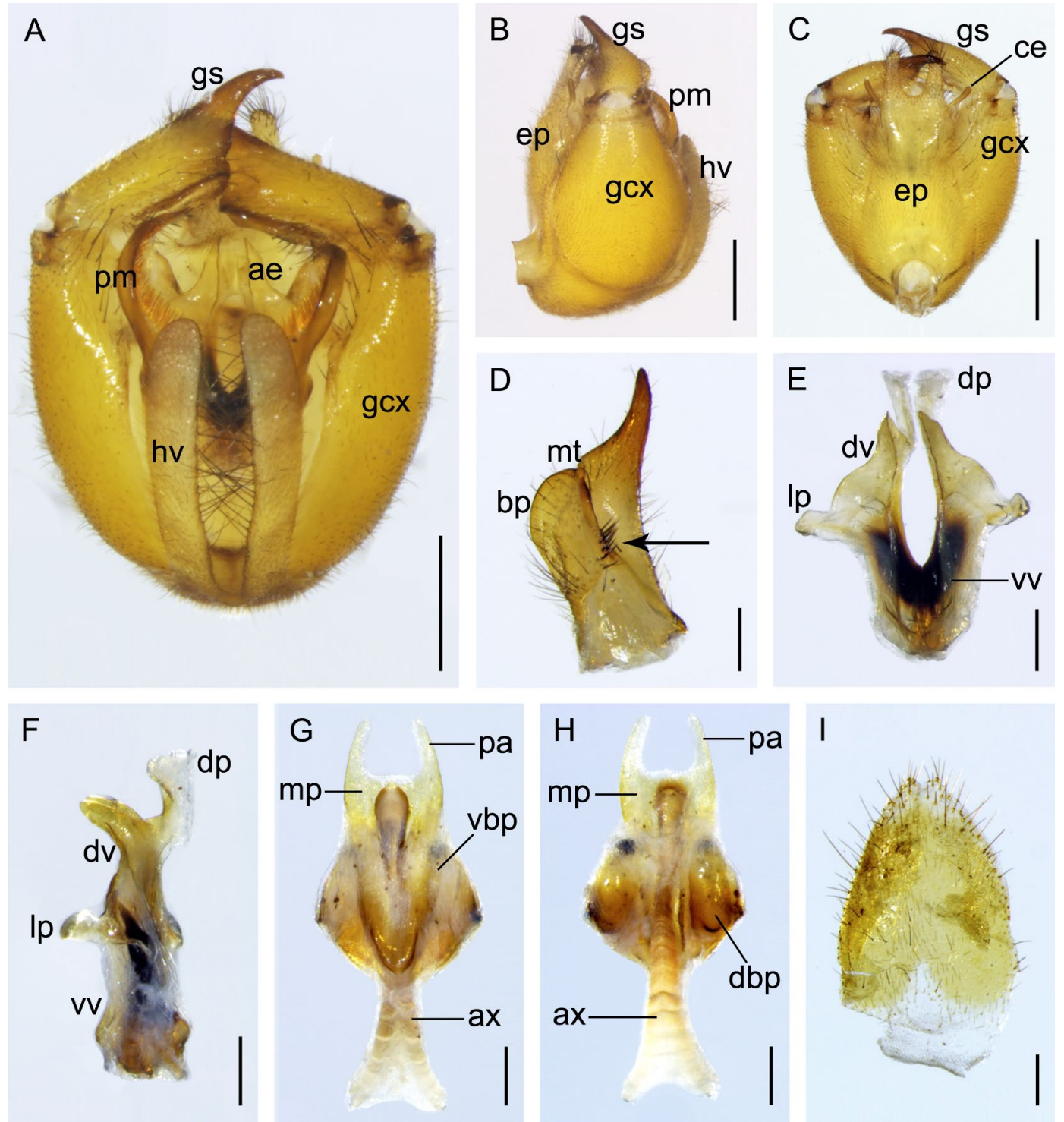

Fig. 8. Genitalia of Cerapanorpa taizishana sp. nov. A-C. Male genital bulb in ventral, lateral and dorsal views. D. Gonostylus in lateral views, arrow indicates the stout setae. E-F. Aedeagus in ventral and lateral views. G-H. Female medigynium in ventral view and dorsal views. I. Subgenital plate in ventral view. Abbreviations: $\mathrm{ae}=$ aedeagus; $\mathrm{ax}=$ axis; $\mathrm{bp}=$ basal process; $\mathrm{ce}=$ cercus; $\mathrm{dbp}=$ dorsal basal plate; $\mathrm{dp}=$ dorsal process; $\mathrm{dv}=$ dorsal valve; $\mathrm{ep}=$ epandrium; gcx = gonocoxite; gs = gonostylus; $\mathrm{hv}=$ hypovalve; $\mathrm{lp}=$ lateral process $; \mathrm{mp}=$ main plate $\mathrm{mt}=$ median tooth $; \mathrm{pa}=$ posterior arm; $\mathrm{pm}=$ paramere; $\mathrm{vbp}=$ ventral basal plate; $\mathrm{vv}=$ ventral valve. Scale bars: $\mathrm{A}-\mathrm{C}=0.5 \mathrm{~mm} ; \mathrm{D}-\mathrm{I}=0.2 \mathrm{~mm}$. 


\section{Remarks}

Cerapanorpa taizishana sp. nov. resembles C. nanwutaina and C. obtusa in appearance from the Qinling Mountains, but is readily distinguished from the latter two species by the conspicuously hook-shaped paramere, L-shaped dorsal process of aedeagus, and specific medigynium.

\section{Cerapanorpa xuebaodinga sp. nov.}

urn:1sid:zoobank.org:act:E6D60D9A-F5EE-4B69-88E3-54628C6966C1

Figs 9-10

\section{Diagnosis}

The new species can be readily recognized by the following features: rostrum uniformly yellowish (Fig. 9C); hypovalves slender, with sparse short bristles along inner margins (Fig. 10A); parameres twisted in knee-shape, bearing long spines apically (Fig. 10D); dorsal valves of aedeagus brawny, expanded apically (Fig. 10E); main plate of medigynium flat, twice as long as wide, intensely constricted medially (Fig. 10G).

\section{Etymology}

The specific name refers to the type locality, Xuebaoding (Snow Treasure Peak) of the Minshan Mountains.

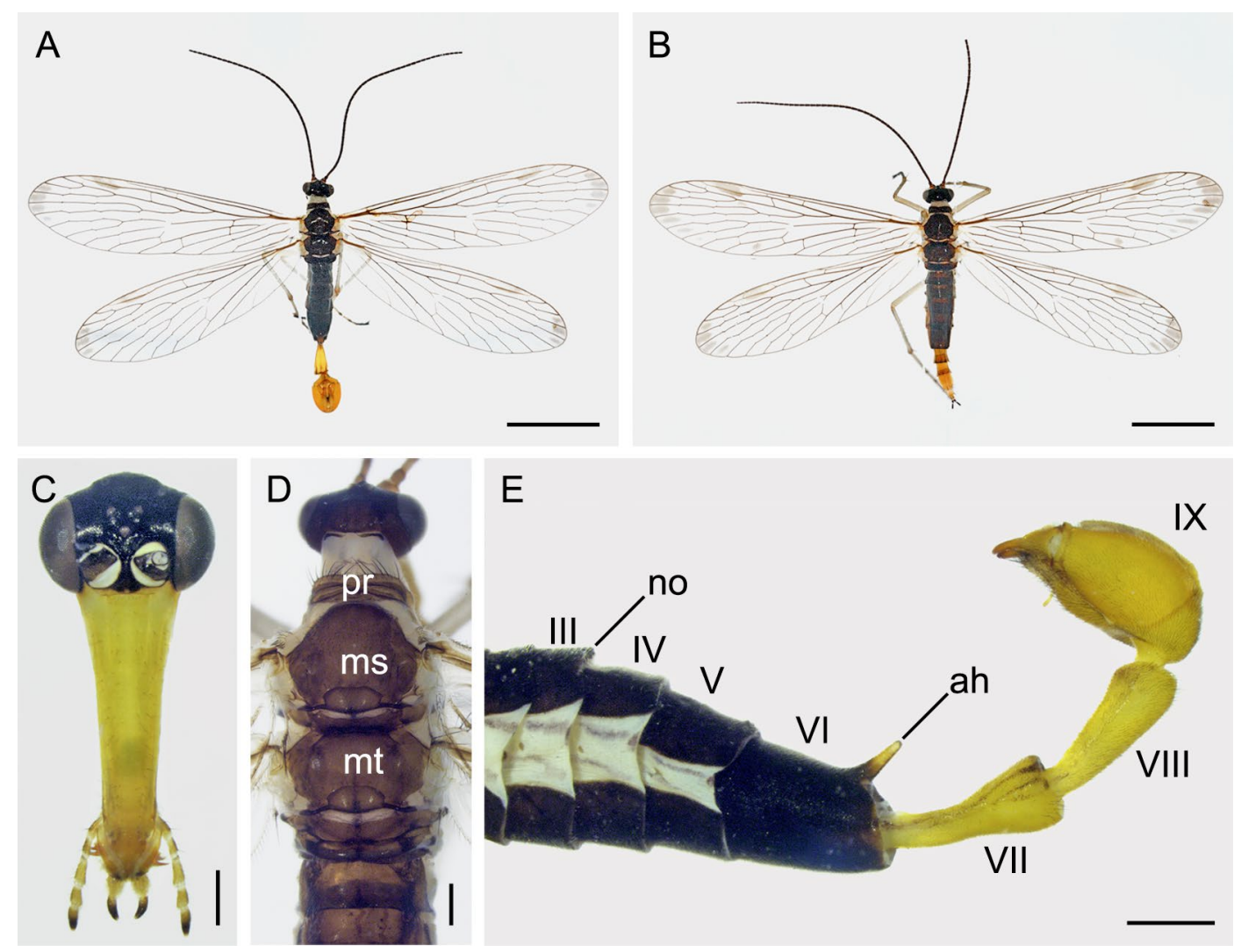

Fig. 9. Adults of Cerapanorpa xuebaodinga sp. nov. A. Male habitus in dorsal view. B. Female habitus in dorsal view. C. Male head with antennae removed in frontal view. D. Dorsum of male. E. Male abdomen in lateral view. Abbreviations: $\mathrm{ah}=$ anal horn; $\mathrm{ms}=$ mesonotum; $\mathrm{mt}=$ metanotum; no $=$ notal organ; $\mathrm{pr}=$ pronotum. Scale bars: $\mathrm{A}-\mathrm{B}=5 \mathrm{~mm} ; \mathrm{C}-\mathrm{D}=0.5 \mathrm{~mm} ; \mathrm{E}=1 \mathrm{~mm}$. 


\section{Type material}

\section{Holotype}

CHINA - O'; Sichuan Province, Pingwu County, Xuebaoding Nature Reserve; $32^{\circ} 30^{\prime} 14^{\prime \prime} \mathrm{N}, 103^{\circ} 56^{\prime} 31^{\prime \prime} \mathrm{E}$; 2200-2500 m a.s.1.; 30 May 2018; Kai Gao \& Yu-Ru Yang leg.; NWAU.

\section{Paratypes}

CHINA • 8 ふぇ, 5 q $\propto$; same data as for holotype; NWAU.

\section{Description}

Male

HEAD. Frons, vertex and occiput brownish black (Fig. 9C-D). Rostrum uniformly yellowish, mandibles yellowish brown; maxillary and labial palps yellow with distal segments dark brown (Fig. 9C). Antennae brownish with 39-42 segments.

Thorax. Pronotum brown, with 12-14 stout setae along anterior margin. Meso- and metanotum grayish brown (Fig. 9D). Pleura light creamy white. Legs pale yellow, tibia with a pair of brown apical spurs; tarsi deep brown at the distal portion. Forewing length 13.7-14.6 mm, width 3.3-3.6 mm. Wing broad and membrane hyaline, almost without markings, except for the weak pterostigmal band (Fig. 9A); apical band faint, only with dark gray trace at apical region. Hindwing length $12.2-13.7 \mathrm{~mm}$, width 3.1-3.5 mm, similar to forewing in pattern (Fig. 9A).

ABDOMEn. T1-T5 blackish, pleura ivory (Fig. 9E). Notal organ on posterior margin of T3 not prominent, postnotal organ on T4 very small, hook-shaped and projecting forward. A6 less than twice as long as A5, with a finger-like anal horn on posterior margin (Fig. 9E). A7 yellowish brown, with a narrow groove at base, constricted at basal half and slightly thicker towards apex. A8 light yellow, as long as A7, gradually thickening apically (Fig. 9E).

Genitalia. Genital bulb yellowish and elliptical (Fig. 10A-D). Epandrium extending beyond apex of gonocoxite, with a deep U-shaped terminal emargination between two stout setose lobes, bearing two clusters of dense long bristles on distal portion (Fig. 10C). Hypovalves of hypandrium slender, almost reaching apex of gonocoxite, with a column of sparse short bristles along inner margin (Fig. 10A). Gonocoxite approximately twice as long as gonostylus, with two subtriangular subapical teeth on ventral submedian margin. Gonostylus bearing a prominent basal process and an indistinct middle tooth on inner margin (Fig. 10A, D). Parameres yellowish brown and geniculate on apical portion, almost reaching apex of gonocoxite, bearing long spines apically (Fig. 10D). Dorsal valves of aedeagus brawny and inflated apically, almost reaching distal border of gonocoxite; ventral valves short, membranous; a small narrow lateral process from basal margin of dorsal valves (Fig. 10E).

\section{Female}

HEAD, THORAX AND ABDOMEN. Similar to those of male in coloration and patterns (Fig. 9B). Forewing length $14.0-15.3 \mathrm{~mm}$, width $3.5-3.8 \mathrm{~mm}$, markings and venations similar to male except for the more distinct pterostigmal band; hindwing length $13.9-15.1 \mathrm{~mm}$, width $3.3-3.7 \mathrm{~mm}$, similar to forewings (Fig. 9B).

GeNitalia. Subgenital plate lingulate, with a trapezoidal emargination terminally, bearing long setae on lateral distal margin (Fig. 10H). Medigynium small and sclerotized; the main plate flat, twice as long as wide, intensely constricted medially (Fig. 10G). Paired posterior arms gradually narrowing toward apex, forming a deep U-shaped emargination (Fig. 10F-G). Ventral basal plates translucent, covering approximately three-quarters of the main plate (Fig. 10H). At the base of the main plate, paired dorsal 
basal plates circular and membranous (Fig. 10G). Axis elongate, with apex slightly extruding out of main plate, and base bifurcated, slightly extending beyond main plate (Fig. 10F-G).

\section{Distribution}

Sichuan Province, China.
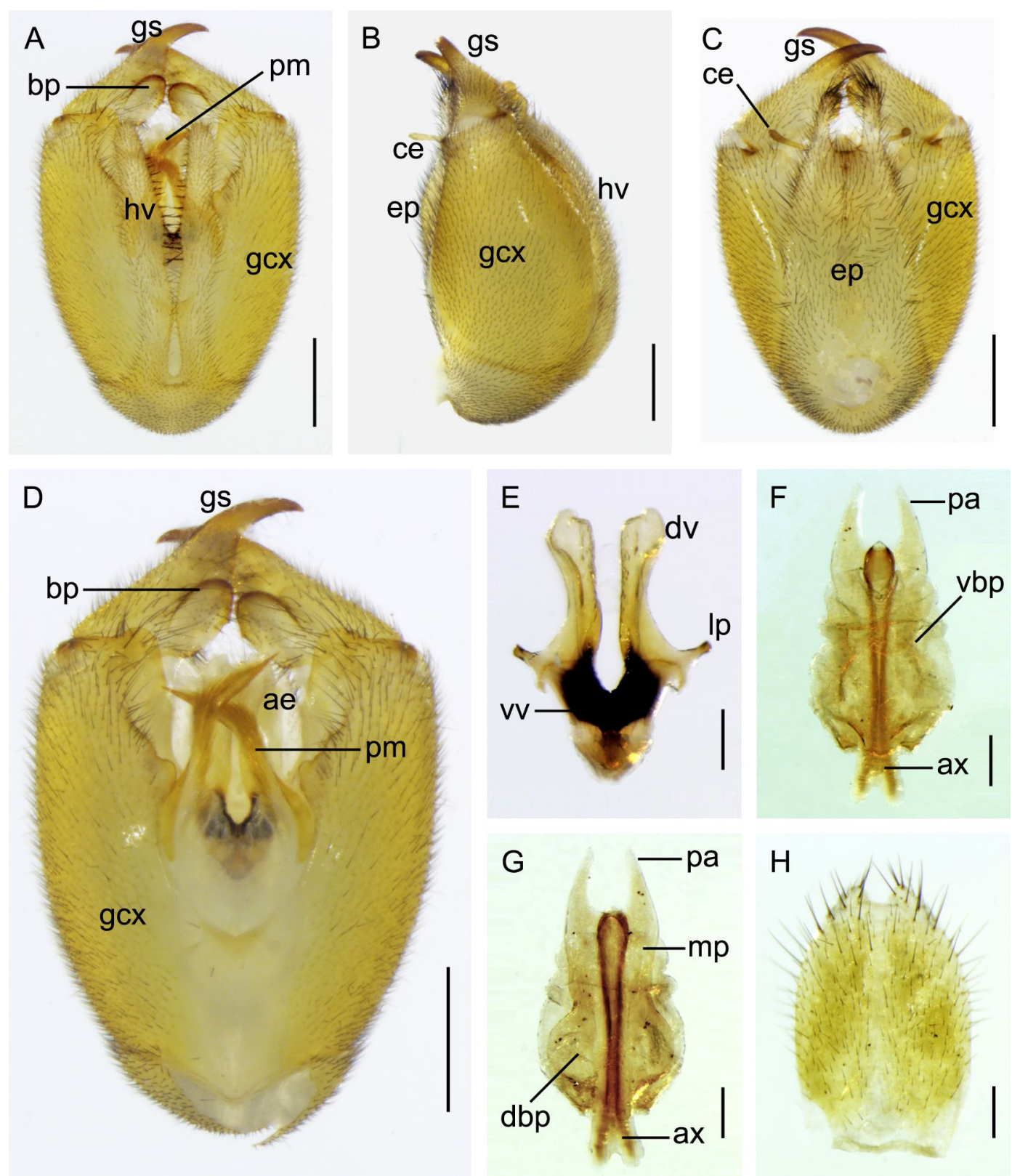

Fig. 10. Genitalia of Cerapanorpa xuebaodinga sp. nov. A-C. Male genital bulb in ventral, lateral and dorsal views. D. Male genital bulb with hypandrium removed in ventral view. E. Aedeagus in ventral view. F-G. Female medigynium in ventral and dorsal views. H. Female subgenital plate in ventral view. Abbreviations: $\mathrm{ae}=$ aedeagus; $\mathrm{ax}=\mathrm{axis} ; \mathrm{bp}=$ basal process; $\mathrm{ce}=$ cercus; $\mathrm{dbp}=$ dorsal basal plate; $\mathrm{dv}=$ dorsal valve; $\mathrm{ep}=$ epandrium; $\mathrm{gcx}=$ gonocoxite; gs = gonostylus; $\mathrm{hv}=$ hypovalve; $\mathrm{lp}=$ lateral process $; \mathrm{mp}=$ main plate; $\mathrm{pa}=$ posterior arm $; \mathrm{pm}=$ paramere $; \mathrm{vbp}=$ ventral basal plate; $\mathrm{vv}=$ ventral valve. Scale bars: $\mathrm{A}-\mathrm{D}=0.5 \mathrm{~mm}$; $\mathrm{E}-\mathrm{H}=0.2 \mathrm{~mm}$. 


\section{Remarks}

The new species resembles C. brevicornis (Hua \& Li, 2007) from the Bashan Mountains in body coloration and the wings pattern, but is easily separated from the latter by the shape of geniculate parameres and the brawny dorsal valves of aedeagus.

\section{Cerapanorpa yanggashana sp. nov.}

urn:lsid:zoobank.org:act:3D6DAD98-3214-47D2-A9C9-CFAB08E58F80

Figs $11-12$

\section{Diagnosis}

The new species can be readily distinguished from its congeners by the following characters: rostrum uniformly brownish black (Fig. 11C); hypovalves slender and prominently elongate, extending beyond the apex of gonocoxite (Fig. 12A); parameres columnar, bearing a column of long golden spines along dorsal side and a brown stout spine apically (Fig. 12A, E); the main plate of medigynium broad at basal half, gradually tapering distally, slightly infolded dorsad (Fig. 12F); ventral basal plates fused into membrane enfolding the main plate, covering almost two-thirds of the main plate in both ventral and dorsal views (Fig. 12F).

\section{Etymology}

The specific epithet refers to its type locality, Yanggashan, Wenxian County, Gansu Province.

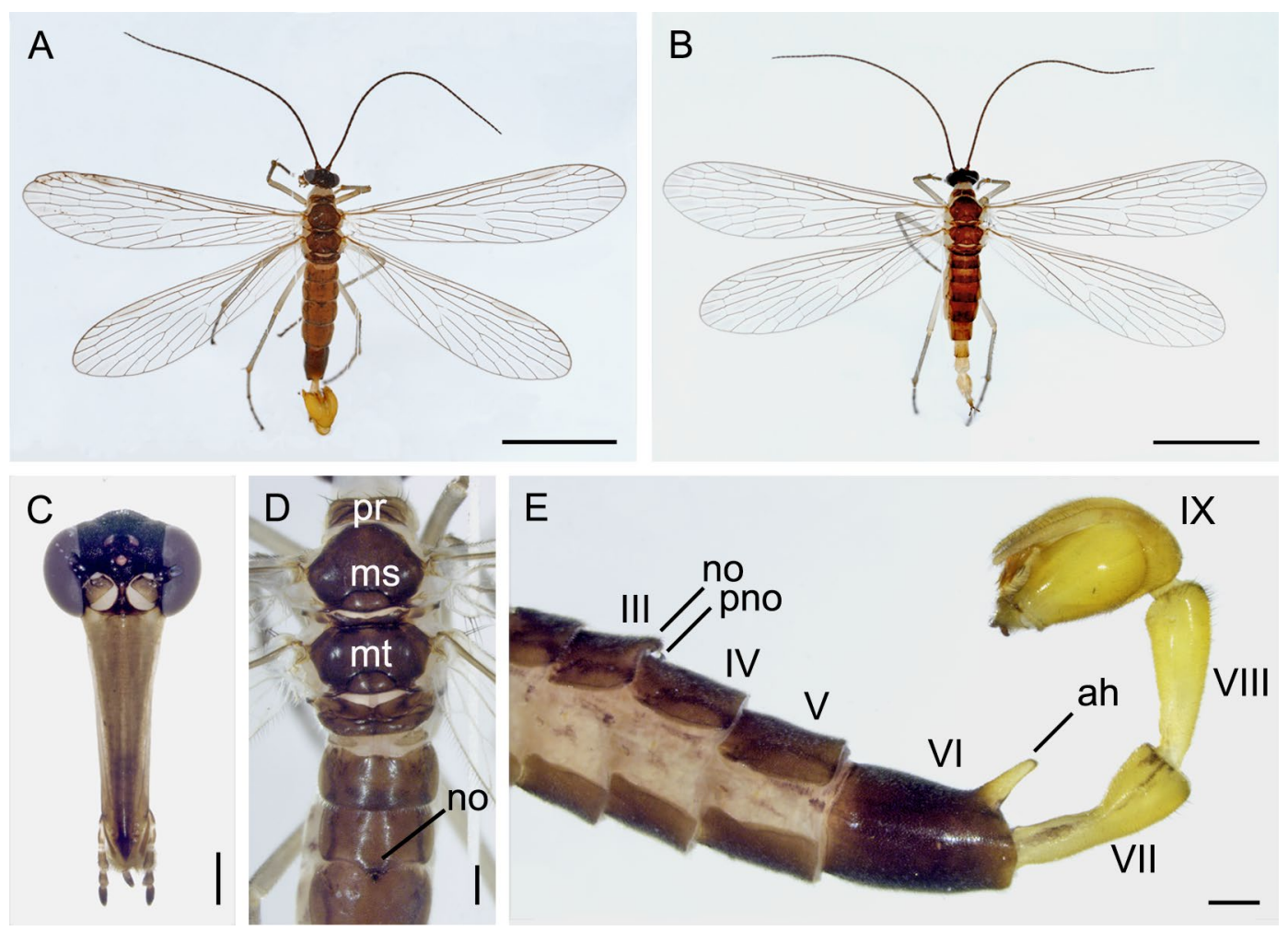

Fig. 11. Adults of Cerapanorpa yanggashana sp. nov. A. Male habitus in dorsal view. B. Female habitus in dorsal view. C. Male head with antennae removed in frontal view. D. Dorsum of male. E. Male abdomen in lateral view. Abbreviations: $\mathrm{ah}=$ anal horn; $\mathrm{ms}=$ mesonotum; $\mathrm{mt}=$ metanotum; no $=$ notal organ; pno $=$ postnotal organ; $\mathrm{pr}=$ pronotum. Scale bars: $\mathrm{A}-\mathrm{B}=5 \mathrm{~mm} ; \mathrm{C}-\mathrm{E}=0.5 \mathrm{~mm}$. 


\section{Type material}

\section{Holotype}

CHINA - I'; Gansu Province, Wenxian County, Mount Yanggashan; 3251'41" N, 104³3'13" E; $2100 \mathrm{~m}$ a.s.1.; 7 Jun. 2018; Kai Gao \& Yu-Ru Yang leg.; NWAU.

\section{Paratypes}

CHINA 7 §ึ̂, 3 q $q$; same data as for holotype; NWAU.

\section{Description}

\section{Male}

HEAD. Frons, vertex and occiput entirely brownish black. Rostrum uniformly brownish black, mandibles, labial and maxillary palps dark brown (Fig. 11C). Antennae filiform, brownish black, with 38-42 flagellomeres.
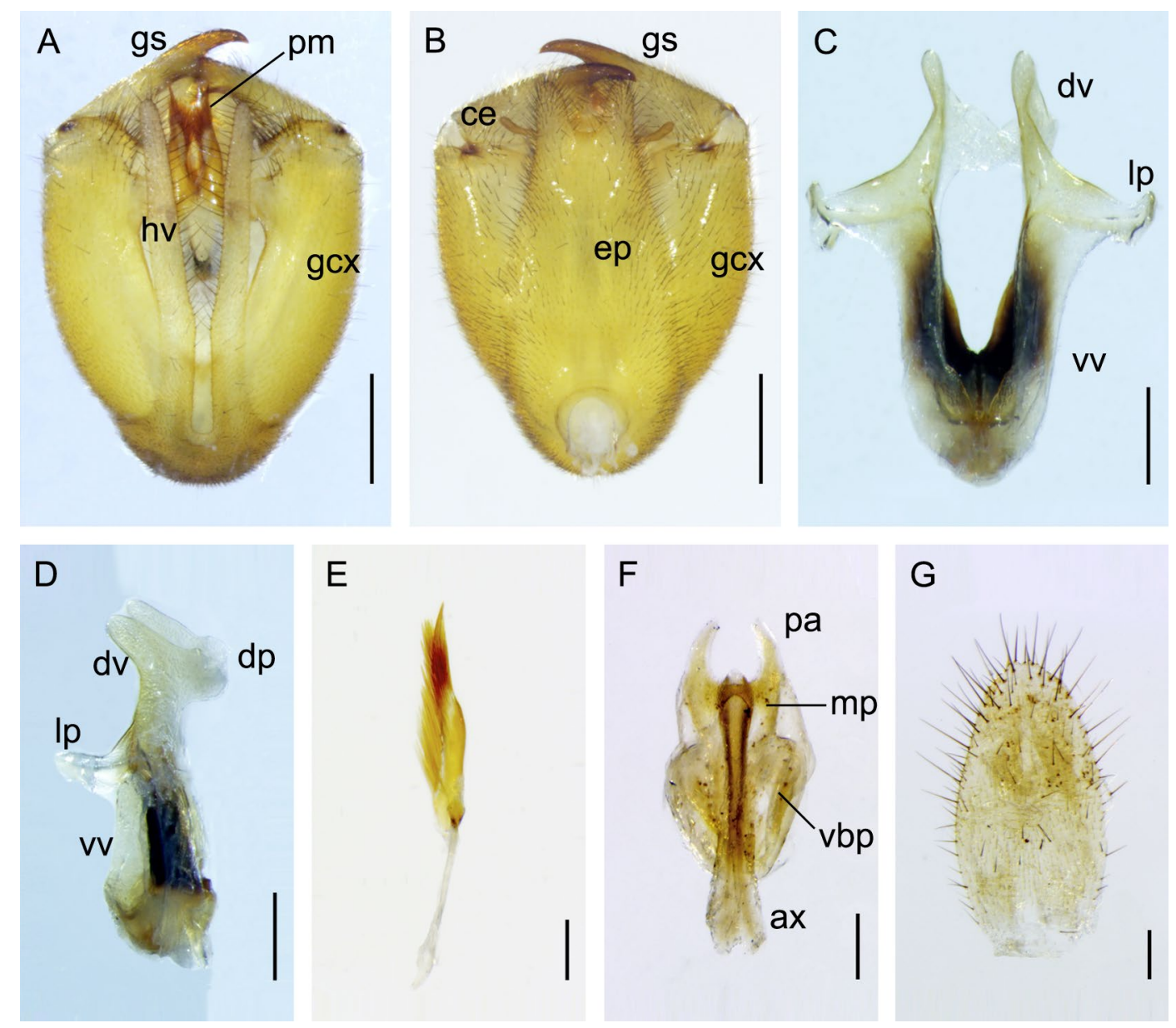

Fig. 12. Genitalia of Cerapanorpa yanggashana sp. nov. A-B. Male genital bulb in ventral and dorsal views. C-D. Aedeagus in ventral and lateral views. E. Left paramere in lateral view. F. Female medigynium in ventral view. G. Female subgenital plate in ventral view. Abbreviations: ax = axis; $\mathrm{ce}=$ cercus; $\mathrm{dp}=$ dorsal process; $\mathrm{dv}=$ dorsal valve; $\mathrm{ep}=$ epandrium; $\mathrm{gcx}=$ gonocoxite; $\mathrm{gs}=$ gonostylus; $\mathrm{hv}=$ hypovalve; $\mathrm{lp}=$ lateral process; $\mathrm{mp}=$ main plate; $\mathrm{pa}=$ posterior $\mathrm{arm} ; \mathrm{pm}=$ paramere; $\mathrm{vbp}=$ ventral basal plate; $\mathrm{vv}=$ ventral valve. Scale bars: $\mathrm{A}-\mathrm{B}=0.5 \mathrm{~mm} ; \mathrm{C}-\mathrm{G}=0.2 \mathrm{~mm}$. 
Thorax. Pronotum light brown, with 10-12 black setae along its anterior margin; Meso- and metanotum dark brown (Fig. 11D). Pleura pale and legs ivory, tibia with a pair of apical spurs; tarsi darkened toward apices. Forewing length $12.2-13.0 \mathrm{~mm}$, width $3.0-3.3 \mathrm{~mm}$. Wing membrane hyaline and almost without marking, pterostigmal band pale. Hindwing length $11.8-12.1 \mathrm{~mm}$, width $2.9-3.2 \mathrm{~mm}$, similar to forewings in pattern (Fig. 11A).

ABDOMEN. T1-T5 brownish black, the corresponding sterna slightly pale. Notal organ of T3 semicircular (Fig. 11E). T4 bearing a small barb-shaped postnotal organ near the anterior margin. T6 entirely brownish black, with a yellow finger-like anal horn on posterior margin. A7 and A8 yellowish and elongate, with basal half slightly constricted and gradually thickening toward the distal portion (Fig. 11E).

Genitalia. Genital bulb globular and yellowish orange (Fig. 12A-B). Epandrium broad at base, gradually narrowing toward apex, with a nearly trapezoidal emargination distally (Fig. 12B). A pair of parallel hypovalves slender and dramatically elongate, extending beyond the apex of gonocoxite, with long bristles along inner margins (Fig. 12A). Gonocoxite bearing a bundle of long setae on inner portion of ventral apex, and two prominently subtriangular subapical teeth on ventro-distal apex (Fig. 12A). Gonostylus much shorter than gonocoxite, medially curved, with a large basal process and an indistinct median tooth on inner margin (Fig. 12A). Parameres columnar, slightly curved dorsal, extending to base of gonostylus, and bearing a column of long golden spines along dorsal side and a brown stout spine apically (Fig. 12A, E). Dorsal valves of aedeagus short, curved ventrally, with distal part pediform (Fig. 12C-D); ventral valves membranous; lateral process auriform and prominent (Fig. 12C-D).

\section{Female}

HeAd, thorax AND ABDOMEN. Similar to males in coloration and patterns. Forewing length 13.0-13.4 mm, width 3.1-3.4 mm, markings and venations similar to male; hindwing length $12.8-13.1 \mathrm{~mm}$, width 3.0-3.2 mm, similar to forewing (Fig. 11B).

Genitalia. Subgenital plate long elliptical and not pointed, ended with a small V-shaped incision, bearing long setae on distal portion (Fig. 12G). Medigynium weakly sclerotized; main plate broad in basal half, gradually narrowing distally, slightly infolded dorsad. Paired posterior arms tapering apically, forming a deep U-shaped emargination (Fig. 12F). Ventral basal plates translucent, fused into membrane enfolding the main plate, covering approximately two-thirds of main plate in both ventral and dorsal side. Paired dorsal basal plates large, semicircular and poorly sclerotized. Axis elongate and bifurcate, slightly extending beyond the main plate (Fig. 12F).

\section{Distribution}

Gansu Province, China.

\section{Remarks}

Cerapanorpa yanggashana sp. nov. resembles C. liupanshana Gao, Ma \& Hua, 2016 in appearance from the Liupan Mountains, Ningxia, but is readily recognized from the latter by the distinct slender and elongate hypovalves, the specific shape of parameres and the foot-shaped dorsal valves of aedeagus.

Cerapanorpa yanggashana sp. nov. has a similar geographical distribution in southern Gansu to C. bonis (Cheng, 1949), which was described based only on a single female specimen. The male of $C$. bonis remains unknown to date. C. yanggashana differs from the latter by subgenital plate long elliptical and not pointed at apex; main plate of medigynium broad at basal half, and slightly infolded dorsad (cf. subgenital plate is pointed; main plate is slender). 


\section{Discussion}

The genus Cerapanorpa is taxonomically revised based on comparative morphology, molecular phylogeny, cytogenetics and geographical data. Four new species are described, and six species are transferred back to Panorpa. Therefore, a total of nineteen species are currently recognized in Cerapanorpa.

Five northeastern Asian species are transferred back to Panorpa, i.e., P. acutipennis Hua, 1998; P. arakavae Miyaké, 1913; P. cornigera MacLachlan, 1887; P. fulvicaudaria Miyaké, 1910 and P. gokaensis Miyaké, 1910. Although these species also bear a single anal horn on the posterior margin of T6 in males, they differ conspicuously from the true Cerapanorpa in genitalia (Issiki 1929; Hua 1998; Gao et al. 2016). A recent molecular phylogenetic analysis (Miao et al. 2019) reveals that the northeastern Asian species are paraphyletic with Panorpa, rather than forming a monophyletic clade with the true Cerapanorpa. Panorpa acutipennis from the Changbai Mountains in Jilin Province has a chromosome number $n=23$, whereas true species of Cerapanorpa have the chromosome number $n=22$ (Miao et al. 2017, 2019). In addition, the geographical distributions are distinctly separated from each other. The true Cerapanorpa is mainly distributed in the Qinling-Bashan Mountains, Minshan Mountains and their adjacent regions in central China (Gao et al. 2016; Wang \& Hua 2017), whereas the northeastern Asian species are spread all over northeastern China, the Korean Peninsula, the Russian Far East and the Japanese archipelago (Gao et al. 2016; Miao et al. 2019). Hence, these species should be transferred back to Panorpa, at least temporarily.

The genus Cerapanorpa as amended currently consists of 19 valid species, which exclusively occur in the mountainous regions of central China. These closely related species not only have uniform appearance and internal anatomy (Hou \& Hua 2008; Liu \& Hua 2009; Ma et al. 2011), but also have a strongly supported monophyly by phylogenetic analyses (Ma et al. 2011; Hu et al. 2015; Miao et al. 2017). The salivary glands of males uniformly possess six secretory tubes with similar size and configuration (Ma et al. 2011). The female medigynium bears an elongate rod-like axis with a pair of weakly divergent arms and paired basal plates on both sides of the main plate (Ma et al. 2012; Gao et al. 2016). All the species of Cerapanorpa from central China are evolutionarily independent entities, and their monophyly is confirmed by phylogenetic analyses based on morphological characters and molecular data (Ma et al. 2012; Miao et al. 2017, 2019). Furthermore, species of Cerapanorpa not only display achiasmate meiosis, but also show a plesiomorphic karyotype with a diploid chromosome number of $2 n=43$ and an X0 sex chromosome system in males (Miao et al. 2017, 2019).

The species diversity of Cerapanorpa in the Minshan Mountains seems to have been greatly underestimated and poorly explored to date (Favre et al. 2015; Hu et al. 2019). During our investigations of recent years, four new species (C. baimaensis sp. nov., C. taizishana sp. nov., C. xuebaodinga sp. nov. and $C$. yanggashana sp. nov.) were discovered from the sky islands in the Minshan Mountains and adjacent regions. As a key biodiversity hotspot in the world (Myers et al. 2000; Huang et al. 2006), the Minshan Mountains have experienced drastic and rapid uplift between the late Miocene and late Pliocene, and built into disproportionate fraction of mountain terrain (Royden et al. 2008). The unique heteropical landform and diverse ecozones in this region might have provided a platform for genetic lineages to undergo independent evolution or speciation process owing to the lack of gene flow (Fjeldså et al. 2012; He \& Jiang 2014; Xing \& Ree 2017). In addition, climatic oscillations in the Quaternary had profound effects on organisms in this region, such as range shifts or extinctions, species-level diversification, and driving local adaptation (Hewitt 2000, 2004; Gu et al. 2013; Zhou et al. 2013; Hu et al. 2019). Therefore, with little doubt, additional new species or distribution records await to be discovered in the poorly explored Minshan Mountains and adjacent regions. 
The genus Panorpa is regarded as a paraphyletic group based on morphological characters (Willmann 1977; Ma et al. 2011, 2012) and molecular data (Misof et al. 2000; Hu et al. 2015; Miao et al. 2019). Although several genera have recently been separated from Panorpa, including Sinopanorpa Cai \& Hua, 2008; Furcatopanorpa Ma \& Hua, 2011; Dicerapanorpa Zhong \& Hua, 2013; Cerapanorpa Gao, Ma \& Hua, 2016 and Megapanorpa Wang \& Hua, 2019, the paraphyly problem of Panorpa has not been thoroughly resolved. More intensive phylogenetic analyses of Panorpidae at the global scale are needed to rationally solve the paraphyly of Panorpa.

\section{Acknowledgments}

We are grateful to Ji-Shen Wang and Lu Jiang for taking photographs, and to Ji-Shen Wang, Gui-Lin Hu and Shuang Xue for commenting the early draft of the manuscript. We also thank Zi-Wei Yin (Shanghai Normal University) for arranging the loan of some specimen, Chang-Lin Li (Xuebaoding Nature Reserve), Yu-Ru Yang (NWAU) and Yuan Hua (NWAU) for the assistance in collecting specimens. This research was supported by the National Natural Science Foundation of China (Grant Nos. 31672341 and 31172125).

\section{References}

Carpenter F.M. 1938. Mecoptera from China, with descriptions of new species. Proceedings of the Entomological Society of Washington 40: 267-281.

Chen Q.-X., Li T. \& Hua B.-Z. 2012. Ultrastructure of the larval eye of the scorpionfly Panorpa dubia (Mecoptera: Panorpidae) with implications for the evolutionary origin of holometabolous larvae. Journal of Morphology 273: 561-571. https://doi.org/10.1002/jmor.20001

Cheng F.Y. 1957. Revision of the Chinese Mecoptera. Bulletin of the Museum of Comparative Zoology 116: $1-117$.

Favre A., Päckert M., Pauls S.U., Jähnig S.C., Uhl D., Michalak I. \& Muellner-Riehl A.N. 2015. The role of the uplift of the Qinghai-Tibetan Plateau for the evolution of Tibetan biotas. Biological Reviews 90: 236-253. https://doi.org/10.1111/brv.12107

Fjeldså J., Bowie R.C.K. \& Rahbek C. 2012. The role of mountain ranges in the diversification of birds. Annual Review of Ecology, Evolution, and Systematics 43: 249-265.

https://doi.org/10.1146/annurev-ecolsys-102710-145113

Gao C., Ma N. \& Hua B.-Z. 2016. Cerapanorpa, a new genus of Panorpidae (Insecta: Mecoptera) with descriptions of three new species. Zootaxa 4158: 93-104. https://doi.org/10.11646/zootaxa.4158.1.5

Gu L.-Y., Liu Y., Que P.-J. \& Zhang Z.-W. 2013. Quaternary climate and environmental changes have shaped genetic differentiation in a Chinese pheasant endemic to the eastern margin of the QinghaiTibetan Plateau. Molecular Phylogenetics and Evolution 67: 129-139.

https://doi.org/10.1016/j.ympev.2012.12.013

He K. \& Jiang X.-L. 2014. Sky islands of southwest of China. I: an overview of phylogeographic patterns. Chinese Science Bulletin 59: 585-597. https://doi.org/10.1007/s11434-013-0089-1

Hewitt G.M. 2000. The genetic legacy of the Quaternary ice ages. Nature 405: 907-913. https://doi.org/10.1038/35016000

Hewitt G.M. 2004. Genetic consequences of climatic oscillations in the Quaternary. Philosophical Transactions of the Royal Society of London B: Biological Sciences 359: 183-195.

https://doi.org/10.1098/rstb.2003.1388 
Hou X.-Y. \& Hua B.-Z. 2008. Structures of the female reproductive systems in Panorpidae (Mecoptera) with remarks on their taxonomic significance. Acta Zootaxonomica Sinica 33: 427-434.

Hu G.-L., Yan G., Xu H. \& Hua B.-Z. 2015. Molecular phylogeny of Panorpidae (Insecta: Mecoptera) based on mitochondrial and nuclear genes. Molecular Phylogenetics and Evolution 85: 22-31.

https://doi.org/10.1016/j.ympev.2015.01.009

Hu G.-L., Hua Y., Hebert P.D.N. \& Hua B.-Z. 2019. Evolutionary history of the scorpionfly Dicerapanorpa magna (Mecoptera, Panorpidae). Zoologica Scripta 48: 93-105. https://doi.org/10.1111/zsc.12326

Hua B.-Z. 1998. Panorpa in Changbai Mountains with descriptions of four new species (Mecoptera: Panorpidae). Entomotaxonomia 20: 37-43.

Huang X.-L., Qiao G.-X. \& Lei F.-M. 2006. Diversity and distribution of aphids in the Qinghai-Tibetan Plateau-Himalayas. Ecological Entomology 31: 608-615.

https://doi.org/10.1111/j.1365-2311.2006.00819.x

Issiki S. 1929. Descripitions of new species of the genus Panorpa from Japan and Formosa. Journal of the Society of Tropical Agriculture 1: 182-191.

Jiang L. \& Hua B.-Z. 2015. Morphological comparison of the larvae of Panorpa obtusa Cheng and Neopanorpa lui Chou \& Ran (Mecoptera: Panorpidae). Zoologischer Anzeiger 255: 62-70.

https://doi.org/10.1016/j.jcz.2015.02.004

Li X., Hua B.-Z., Cai L.-J. \& Huang P.-Y. 2007. Two new species of Panorpa (Mecoptera: Panorpidae) from Shaanxi, China with notes on their biology. Zootaxa 1542: 59-67.

Liu S.-Y. \& Hua B.-Z. 2009. Morphology and histology of the alimentary canal in scorpionfly Panorpa obtusa (Mecoptera: Panorpidae). Acta Entomologica Sinica 52: 808-813.

http://www.insect.org.cn/EN/Y2009/V52/I7/808

Ma N., Cai L.-J. \& Hua B.-Z. 2009. Comparative morphology of the eggs in some Panorpidae (Mecoptera) and their systematic implication. Systematics and Biodiversity 7: 403-417.

https://doi.org/10.1017/S1477200009990107

Ma N., Liu S.-Y. \& Hua B.-Z. 2011. Morphological diversity of male salivary glands in Panorpidae (Mecoptera). European Journal of Entomology 108: 493-499. https://doi.org/10.14411/eje.2011.064

Ma N., Zhong W., Gao Q.-H. \& Hua B.-Z. 2012. Female genital plate diversity and phylogenetic analyses of East Asian Panorpidae (Mecoptera). Systematics and Biodiversity 10: 159-178.

https://doi.org/10.1080/14772000.2012.683459

Miao Y., Ma N. \& Hua B.-Z. 2017. Cytotaxonomy and molecular phylogeny of the genus Cerapanorpa Gao, Ma \& Hua, 2016 (Mecoptera: Panorpidae). Scientific Reports 7: 4493.

https://doi.org/10.1038/s41598-017-04926-9

Miao Y., Wang J.-S. \& Hua B.-Z. 2019. Molecular phylogeny of the scorpionflies Panorpidae (Insecta: Mecoptera) and chromosomal evolution. Cladistics 1-16. https://doi.org/10.1111/cla.12357

Misof B., Erpenbeck D. \& Sauer, K.P. 2000. Mitochondrial gene fragments suggest paraphyly of the genus Panorpa (Mecoptera, Panorpidae). Molecular Phylogenetics and Evolution 17: 76-84.

https://doi.org/10.1006/mpev.2000.0817

Myers N., Mittermeier R.A., Mittermeier C.G., da Fonseca G.A.B. \& Kent J. 2000. Biodiversity hotspots for conservation priorities. Nature 403: 853-858. https://doi.org/10.1038/35002501

Penny N.D. \& Byers G.W. 1979. A check-list of the Mecoptera of the world. Acta Amazonica 9: 365388. https://doi.org/10.1590/1809-43921979092365 
Royden L.H., Burchfiel B.C. \& van der Hilst R.D. 2008. The geological evolution of the Tibetan Plateau. Science 321: 1054-1058. https://doi.org/10.1126/science.1155371

Tang Z., Wang Z., Zheng C. \& Fang J. 2006. Biodiversity in China's mountains. Frontiers in Ecology and the Environment 4: 347-352. https://doi.org/10.1890/1540-9295(2006)004[0347:BICM]2.0.CO;2

Tong X., Zhong W. \& Hua B.-Z. 2018. Copulatory mechanism and functional morphology of genitalia and anal horn of the scorpionfly Cerapanorpa dubia (Mecoptera: Panorpidae). Journal of Morphology 279: 1532-1539. https://doi.org/10.1002/jmor.20903

Wang J.-S. \& Hua B.-Z. 2017. An annotated checklist of the Chinese Mecoptera with description of male Panorpa guttata Navás, 1908. Entomotaxonomia 39: 24-42.

https://doi.org/10.11680/entomotax.2017003

Willmann R. 1977. Zur Phylogenie der Panorpiden Europas (Insecta, Mecoptera). Zeitschrift für Zoologische Systematik und Evolutionforschung 15: 208-231.

https://doi.org/10.1111/j.1439-0469.1977.tb00538.x

Xing Y.-W. \& Ree H.R. 2017. Uplift-driven diversification in the Hengduan Mountains, a temperate biodiversity hotspot. Proceedings of the National Academy of Sciences of the United States of America 114: E3444-E3451. https://doi.org/10.1073/pnas.1616063114

Zhang Y.-L., Li B.-Y. \& Zheng D. 2002. A discussion on the boundary and area of the Tibetan Plateau in China. Geographical Research 21: 1-8. https://doi.org/10.11821/yj2002010001

Zhou W.-W., Yan F., Fu J., Wu S., Murphy R.W., Che J. \& Zhang Y.-P. 2013. River islands, refugia and genetic structuring in the endemic brown frog Rana kukunoris (Anura, Ranidae) of the Qinghai-Tibetan Plateau. Molecular Ecology 22: 130-142. https://doi.org/10.1111/mec.12087

Manuscript received: 1 March 2019

Manuscript accepted: 27 May 2019

Published on: 11 July 2019

Topic editor: Gavin Broad

Desk editor: Pepe Fernández

Printed versions of all papers are also deposited in the libraries of the institutes that are members of the EJT consortium: Muséum national d'Histoire naturelle, Paris, France; Meise Botanic Garden, Belgium; Royal Museum for Central Africa, Tervuren, Belgium; Royal Belgian Institute of Natural Sciences, Brussels, Belgium; Natural History Museum of Denmark, Copenhagen, Denmark; Naturalis Biodiversity Center, Leiden, the Netherlands; Museo Nacional de Ciencias Naturales-CSIC, Madrid, Spain; Real Jardín Botánico de Madrid CSIC, Spain; Zoological Research Museum Alexander Koenig, Bonn, Germany; National Museum, Prague, Czech Republic. 